Pathologe 2021 · 42:103-115 https://doi.org/10.1007/s00292-020-00864-y Online publiziert: 30 . November 2020 (c) Der/die Autor(en) 2020

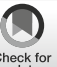

Albrecht Stenzinger ${ }^{1}$ Cornelis M. van Tilburg ${ }^{2}$. Ghazaleh Tabatabai ${ }^{3}$. Florian Länger ${ }^{4} \cdot$ Norbert Graf $^{5} \cdot$ Frank Griesinger ${ }^{6} \cdot$ Lukas C. Heukamp $^{7}$. Michael Hummel $^{8}$. Thomas Klingebiel $^{9}$. Simone Hettmer ${ }^{10}$. Christian Vokuhl ${ }^{11}$. Sabine Merkelbach-Bruse ${ }^{12}$. Friedrich Overkamp ${ }^{13}$. Peter Reichardt ${ }^{14}$. Monika Scheer ${ }^{15}$. Wilko Weichert ${ }^{16} \cdot$ C. Benedikt Westphalen ${ }^{17}$. Carsten Bokemeyer ${ }^{18}$. Philipp Ivanyi ${ }^{19}$. Sonja Loges ${ }^{18,20,23,24}$. Peter Schirmacher ${ }^{1}$. Bernhard Wörmann ${ }^{21} \cdot$ Stefan Bielack ${ }^{15}$. Thomas T. W. Seufferlein ${ }^{22}$

\begin{abstract}
${ }^{1}$ Allgemeine Pathologie und pathologische Anatomie, Pathologisches Institut, Universitätsklinikum Heidelberg, Heidelberg, Deutschland; ${ }^{2}$ Hopp-Kindertumorzentrum Heidelberg (KiTZ), Deutsches Krebsforschungszentrum (DKFZ), Universitätsklinikum Heidelberg, Heidelberg, Deutschland; ${ }^{3}$ Abteilung Neurologie mit interdisziplinärem Schwerpunkt Neuroonkologie, Universitätsklinikum Tübingen und Hertie-Institut für Klinische Hirnforschung, Eberhard Karls Universität Tübingen, Tübingen, Deutschland; ${ }^{4}$ Institut für Pathologie, Medizinische Hochschule Hannover, Hannover, Deutschland; ${ }^{5}$ Klinik für Pädiatrische Onkologie und Hämatologie, Universitätsklinikum des Saarlandes, Medizinische Fakultät, Universität des Saarlandes, Homburg, Deutschland; ${ }^{6}$ Klinik für Hämatologie und Onkologie, Universitätsklinik für Innere Medizin - Onkologie, Pius-Hospital Oldenburg, Oldenburg, Deutschland; ${ }^{7}$ Institut für Hämatopathologie Hamburg, Hamburg, Deutschland; ${ }^{8}$ Institut für Pathologie (CCM), Charité - Universitätsmedizin Berlin, Berlin, Deutschland; ${ }^{9}$ Klinik für Kinder- und Jugendmedizin, Universitätsklinikum Frankfurt, Frankfurt, Deutschland; ${ }^{10}$ Klinik für Pädiatrische Hämatologie und Onkologie, Zentrum für Kinder- und Jugendmedizin, Universitätsklinikum Freiburg, Freiburg, Deutschland; ${ }^{11}$ Sektion Kinderpathologie, Institut für Pathologie, Universitätsklinikum Bonn, Bonn, Deutschland; ${ }^{12}$ Institut für Allgemeine Pathologie und Pathologische Anatomie, Uniklinik Köln, Köln, Deutschland; ${ }^{13}$ OncoConsult Overkamp GmbH, Berlin, Deutschland; ${ }^{14}$ Onkologie und Palliativmedizin, Helios Klinikum Berlin-Buch, Berlin, Deutschland; ${ }^{15}$ Pädiatrie 5 - Onkologie, Hämatologie und Immunologie, Zentrum für Kinder-, Jugend- und Frauenmedizin - Olgahospital, Stuttgart Cancer Center, Klinikum Stuttgart, Stuttgart, Deutschland; ${ }^{16}$ Institut für Allgemeine Pathologie und Pathologische Anatomie, Technische Universität München, München, Deutschland; ${ }^{17}$ Medizinische Klinik und Poliklinik III, Klinikum der Universität München, Ludwig-Maximilians-Universität München, München, Deutschland; ${ }^{18}$ Zentrum für Onkologie, II. Medizinische Klinik und Poliklinik (Onkologie, Hämatologie, Knochenmarktransplantation mit Abteilung für Pneumologie), Universitätsklinikum Hamburg-Eppendorf, Hamburg, Deutschland; ${ }^{19} \mathrm{Klinik}$ für Hämatologie, Hämostaseologie, Onkologie und Stammzelltransplantation, Medizinische Hochschule Hannover, Hannover, Deutschland; ${ }^{20}$ Zentrum für experimentelle Medizin, Institut für Tumorbiologie, Universitätsklinikum Hamburg- Eppendorf, Hamburg, Deutschland; ${ }^{21}$ Medizinische Klinik mit Schwerpunkt Hämatologie, Onkologie und Tumorimmunologie (CVK), Charité - Universitätsmedizin Berlin, Berlin, Deutschland; ${ }^{22}$ Klinik für Innere Medizin I, Universitätsklinikum Ulm, Ulm, Deutschland; ${ }^{23}$ Abteilung für Personalisierte Medizinische Onkologie, Deutsches Krebsforschungszentrum (DKFZ), Heidelberg, Deutschland; ${ }^{24}$ Universitätsklinikum Mannheim, Mannheim, Deutschland
\end{abstract}

\title{
Diagnostik und Therapie von Tumoren mit NTRK-Genfusionen
}

\begin{abstract}
Diagnostik und Therapie vieler Krebserkrankungen haben sich in den letzten Jahren enorm gewandelt. So stehen zunehmend molekular zielgerichtete Therapien und/oder Immuntherapien zur Verfügung, die passgenau zu molekulargenetischen und -pathologischen Veränderungen bei einer bestimmten Tumorerkrankung eingesetzt werden können.
\end{abstract} Dies hat den Stellenwert der moleku-

Beiträge der einzelnen Autoren werden am Beitragsende detailliert aufgeführt. larpathologischen und -genetischen Diagnostik nachhaltig verändert. Jetzt zeichnet sich ein weiterer Schritt ab: eine tumorentitätenübergreifende, möglicherweise sogar "tumoragnostische" Therapiestrategie.

Eines der ersten Beispiele für dieses Konzept sind Inhibitoren der TropomyosinRezeptor-Kinasen (TRK). Deren Einsatz richtet sich nicht primär nach der Tumorentität, sondern nach dem Nachweis der zugrunde liegenden molekularen Verän- derung, der NTRK-Genfusion. Tumoren mit NTRK-Genfusionen sind selten. Dies stellt für die klinischen Prozesse eine große Herausforderung dar: Welcher Patient soll wann und wie von wem getestet werden und wann sollte die Therapie mit einem TRK-Inhibitor begonnen werden? Im Folgenden möchten wir den Hintergrund aktueller Studiendaten sowie einen möglichen Diagnosealgorithmus für TRK-Fusionstumoren vorschlagen und erläutern. 


\section{Zusatzmaterial online}

Die Online-Version dieses Beitrags (https:// doi.org/10.1007/s00292-020-00864y) enthält weitere Quellen, ergänzende Inhalte sowie Tabellen zu Larotrectinib und Entrectinib [Verträglichkeit; Baseline-Charakteristika; Wirksamkeit von Entrectinib bei TRK-Fusionstumoren; Therapiebedingte unerwünschte Ereignisse]. Beitrag und Zusatzmaterial stehen Ihnen auf www. springermedizin.de zur Verfügung. Bitte geben Sie dort den Beitragstitel in die Suche ein, das Zusatzmaterial finden Sie beim Beitrag unter „Ergänzende Inhalte“.

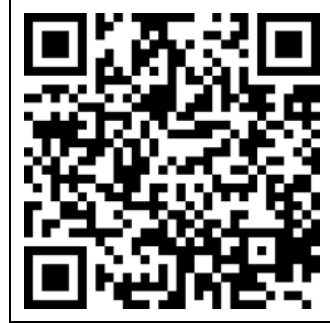

\section{Die TRK-Familie}

Bei den TRK handelt es sich um Rezeptortyrosinkinasen, die physiologisch vorwiegend im menschlichen Nervengewebe exprimiert werden [46]. Diese Transmembranrezeptorfamilie hat 3 Mitglieder: TRKA, TRKB und TRKC [10, 32]. Liganden aller 3 Rezeptoren sind Neurotrophine, die mit hoher Affinität binden [10, 32]. Durch die Ligandenbindung kommt es zu Homodimerisierung (und möglicherweise auch Heterodimerisierung) der transzellulären RezeptorTyrosinkinase mit konsekutiver Aktivierung der Tyrosinkinase und subsequenter Aktivierung verschiedener intrazellulärer Signalwege [10]. Dieses Signal steuert u.a. die neuronale Entwicklung und Differenzierung sowie physiologische neuronale Prozesse [10, 15, 32]: TRKA spielt für Proliferation und Differenzierung von Zellen eine Rolle [2, 59], TRKB-induzierte Signalwege unterstützen die neuronale Differenzierung und das Überleben der Zellen [2, 59]. TRKC ist in Prozesse eingebunden, die die Apoptose verhindern und die Motilität von Zellen fördern [2]. Zusammenfassend sind TRK über verschiedene Signalwege an der Regulation der Motorik, Propriozeption, Schmerzempfindung, Thermoregulation, Gedächtnisleistung,
Stimmung, Appetit und Körpergewicht beteiligt [15].

\section{NTRK-Genfusionen als onkogene Treiber}

Die für TRKA, TRKB und TRKC kodierenden Gene sind NTRK1, NTRK2 und NTRK3 (NTRK= neurotrophe TyrosinRezeptor-Kinase) [10, 32]. Die häufigste Ursache für eine onkogene TRK-Aktivierung ist das Vorliegen von NTRKGenfusionen [10, 32]. Ihnen liegen intraoder interchromosomale Translokationen zugrunde, bei denen das $3^{\prime}$-Ende von NTRK1, NTRK2 oder NTRK3, das die codierenden Abschnitte für die Kinasedomäne enthält, mit dem $5^{\prime}$-Ende verschiedener Gene (i.d.R. aus derselben funktionellen Klasse) [71] verbunden wird, die i.d.R. Dimerisierungsdomänen enthalten. Das daraus translatierte Fusionsprotein (chimäres Onkoprotein) verursacht eine konstitutive (dauerhafte), ligandenunabhängige Aktivierung der TRK-Kinasedomäne [10, 32]. Die dauerhafte Aktivierung der TRK führt zur Aktivierung eines Signalnetzwerks, das u. a. MAP-Kinase, Proteinkinase C (PKC), die Phosphatidylinositol-3-Kinase (PI3K) und AKT umfasst und zur Stimulation von Proliferation bzw. Hemmung von Apoptosesignalen führt [2, 42, 46].

Auf genetischer Ebene sind neben häufigen Fusionsgenen (z.B. ETV6NTRK3) zahlreiche Varianten mit niedriger Prävalenz zu beobachten. Bisher wurden nicht nur über 80 Genfusionspartner identifiziert, sondern auch unterschiedliche, in die Fusion involvierte Exone der Fusionspartner (unterschiedliche Bruchpunkte), sodass die Gesamtzahl aller Varianten weitaus höher liegt [47, 61, 72]. Es ist wichtig festzuhalten, dass sich dieses Bild fortlaufend ändern wird, da anzunehmen ist, dass mit steigender Testrate weitere Fusionsvarianten identifiziert werden.

NTRK-Genfusionen oder TRK-Fusionsproteine sind starke onkogene Treiber bei unterschiedlichen Krebserkrankungen [46]. Das gleichzeitige Auftreten einer NTRK-Genfusion mit anderen starken onkogenen Treibern ist nach derzeitigem Stand der Literatur im TRK-
Inhibitor-naiven Setting selten (Konzept der „mutual exclusivity“ [51]). In Verbindung mit einer spezifischen Morphologie kann der Nachweis einer NTRK-Genfusion die Diagnose unterstützen, z.B. bei sekretorischen Karzinomen der Speicheldrüse oder infantilen Fibrosarkomen (IFS). Zukünftige Studien und Forschungsprojekte sind jedoch notwendig, um zu klären, in welcher Art und Weise und in welchem Umfang der tumorbiologische Kontext, in den die Genfusion eingebettet ist und der durch die Histologie (Tumorentität) angezeigt wird, die onkogene Potenz von NTRK-Genfusionen moduliert und möglicherweise das Therapieansprechen konventioneller wie auch zielgerichteter Therapieansätze bzw. auch die Krankheitsprognose beeinflusst. Auch die Frage, inwieweit NTRKFusionsvarianten die Tumorbiologie und das Therapieansprechen modulieren, ist an Hand der bisherigen Studiendaten nicht abschließend zu klären und bedarf weiterer wissenschaftlicher Untersuchungen. So legen beispielsweise mehrere Berichte zu ALK(anaplastische Lymphomkinase)-positiven Lungenkarzinomen nahe, dass Translokationen mit verschiedenen Fusionspartnern und Bruchpunkten unterschiedliche biologische Eigenschaften aufweisen [68] und mit unterschiedlichen klinischen Therapieverläufen assoziiert $[8,37]$ sein können. Bei genetisch komplexen Tumoren, nachgewiesen bei Osteosarkomen, können NTRK-Fusionen auch zu nichtfunktionalen Genprodukten führen [3].

Mögliche weitere Ursachen für eine onkogene TRK-Aktivierung sind NTRKGenamplifikationen, die bei ca. 2,2\% der metastasierten Karzinome vorkommen können [36], und somatische NTRKPunktmutationen, die die Kinasedomäne von TRKB betreffen, z. B. die NTRK2Mutationen T695I und D751N, die imkolorektalen Karzinom beobachtet wurden [10]. Ferner konnten auch alternative NTRK1-Splicevarianten nachgewiesen werden wie TRKAIII oder $\triangle$ TRKA beim Neuroblastom bzw. bei der akuten myeloischen Leukämie (AML) [10]. Weiterhin ist eine TRK-Überexpression ohne Nachweis einer genetischen Alteration möglich, z.B. bei Tumoren der Brust, der Haut und der Lunge sowie 
beim Neuroblastom. Nach derzeitigem Kenntnisstand ist allerdings unklar, ob diese Veränderungen aus tumorbiologischer und therapeutischer Sicht als den NTRK-Genfusionen gleichwertig anzusehen sind. Zur Klärung dieser Fragestellung sind neben präklinischen Untersuchungen prospektive klinische Studien notwendig.

\section{Häufigkeit von NTRK-Genfusionen}

Insgesamt sind NTRK-Genfusionen selten und nur bei etwa $0,3-0,5 \%$ aller soliden Tumoren nachweisbar $([44,57]$; - Abb. 1). NTRK-Genfusionen finden sich auch bei hämatologischen Krebserkrankungen wie der AML und der akuten lymphatischen Leukämie (ALL) mit einer Prävalenz von maximal 0,1\% [60]. Okamura et al. untersuchten die Prävalenz von NTRK-Genfusionen in fast 13.500 Gewebeproben von Kindern, Heranwachsenden und Erwachsenen mit soliden Tumoren oder hämatologischen Krebserkrankungen [44]. Sie fanden eine Häufigkeit dieser Alterationen von $0,31 \%$ (31 von $9966 \mathrm{Tu}$ morgeweben) bei Erwachsenen und $0,34 \%$ (12 von 3501 Tumorgeweben) bei Kindern und Heranwachsenden. Allerdings haben alle bisherigen Untersuchungen zur Häufigkeit von NTRKGenfusionen Limitationen, da sie hinsichtlich Sensitivität und Spezifität mit sehr unterschiedlichen diagnostischen Methoden durchgeführt wurden und aufgrund der geringen Prävalenz und geringen untersuchten Fallzahlen je Tumorentität die Aussagekraft statistischer Analysen eingeschränkt ist. Dies gilt insbesondere bei Tumortypen mit vergleichsweise niedrigem Vorkommen von NTRK-Genfusionen [42, 44].

Interessanterweise lassen sich NTRKGenfusionen bei bestimmten, seltenen Tumoren häufig nachweisen $([1,10,32]$; - Abb. 1). So ist z. B. die ETV6-NTRK3Fusion mit einer Prävalenz von $>90 \%$ pathognomonisch bei Krebserkrankungen wie dem IFS, dem kongenitalen mesoblastischen Nephrom (CMN, zellulärer Subtyp), dem sekretorischen Mammakarzinom oder dem sekretorischen Speicheldrüsenkarzinom ([10, 64]; • Abb. 1).

Pathologe 2021 · 42:103-115 https://doi.org/10.1007/s00292-020-00864-y

(c) Der/die Autor(en) 2020

A. Stenzinger · C. M. van Tilburg · G. Tabatabai · F. Länger · N. Graf · F. Griesinger ·

L. C. Heukamp - M. Hummel · T. Klingebiel · S. Hettmer · C. Vokuhl · S. Merkelbach-Bruse · F. Overkamp · P. Reichardt - M. Scheer - W. Weichert · C. B. Westphalen · C. Bokemeyer · P. Ivanyi · S. Loges · P. Schirmacher · B. Wörmann · S. Bielack · T. T. W. Seufferlein

\section{Diagnostik und Therapie von Tumoren mit NTRK-Genfusionen}

\section{Zusammenfassung}

NTRK-Genfusionen sind seltene genetische Alterationen, die tumorentitätenübergreifend vorkommen können. Während sie in den meisten soliden Tumoren nur sehr niederfrequent vorkommen, lassen sie sich in bestimmten Tumoren wie dem infantilen Fibrosarkom, dem kongenitalen mesoblastischen Nephrom und dem sekretorischen Mamma- oder Speicheldrüsenkarzinom jedoch häufig nachweisen. NTRK-Genfusionen bzW. TRK-Fusionsproteine gelten als starke onkogene Treiber. Bei Nachweis von NTRKGenfusionen können TRK-Inhibitoren unabhängig von der Tumorentität eingesetzt werden. Vertreter sind Entrectinib und Larotrectinib. Bislang ist nur Larotrectinib in der Europäischen Union zugelassen. Für beide wurden Wirksamkeit und Verträglichkeit in
Phase-I- und Phase-II-Studien gezeigt. Die Seltenheit der TRK-Fusionstumoren stellt diagnostische und klinische Prozesse vor große Herausforderungen: Einerseits sollen alle Patienten mit TRK-Fusionstumoren identifiziert werden, andererseits sind epidemiologische und histologische Aspekte sowie Ressourcen zu berücksichtigen. Basierend auf diesen Punkten möchten wir einen Diagnosealgorithmus für TRKFusionstumoren vorschlagen, außerdem stellen wir aktuelle Daten zu den TRKInhibitoren vor.

Schlüsselwörter NTRK · Genfusion · Translokation · Larotrectinib · Entrectinib

\section{Diagnosis and therapy of tumors with NTRK gene fusion}

\section{Abstract}

NTRK gene fusions are sporadic genetic alterations that can occur across tumor entities. Whereas they are quite rare in most solid tumors they are present at much higher frequencies in certain rare tumors such as infantile fibrosarcoma, congenital mesoblastic nephroma, secretory breast, or salivary gland carcinoma. NTRK gene fusions or TRK fusion proteins are considered strong oncogenic drivers. If NTRK gene fusions are detected, TRK inhibitors such as entrectinib and larotrectinib can be used regardless of the tumor entity. So far only larotrectinib is approved in the European Union. Both drugs have been shown to be effective and well

Die Analyse der derzeit verfügbaren Daten zeigt auf, dass im Gegensatz $\mathrm{zu}$ beispielsweise ALK-Genfusionen, die vorwiegend im nichtkleinzelligen Lungenkarzinom (NSCLC) [52], bei großzelligen Lymphomen [19] und in inflammatorischen myofibroblastischen Tumoren [4] beobachtet werden, die Fusionspartner von NTRK und die involvierten Exone der verschiedenen Gene vielfältiger sind, sodass eine genaue Kenntnis der verfügbaren Methoden tolerated in phase I and phase II studies. The low prevalence of TRK fusion-positive cancers poses challenges for diagnostic and clinical work-flows. On one hand, patients with NTRK gene fusions should be identified; on the other hand, epidemiological, histological, and resource-related aspects have to be taken into account. Based on these premises, we suggest a diagnostic algorithm for TRK fusion cancers and present current data on TRK inhibitors.

\section{Keywords}

NTRK - Gene fusion · Translocation .

Larotrectinib · Entrectinib

zum Nachweis einer NTRK-Genfusion besonders wichtig ist [47].

\section{Diagnostik von NTRK- Genfusionen}

\section{Untersuchungsmethoden}

Die klinische Anwendung von TRKInhibitoren wie Entrectinib oder Larotrectinib setzt den erbrachten Nachweis einer NTRK-Genfusion voraus [5, 21]. In 


\section{Molekulares Tumorboard}

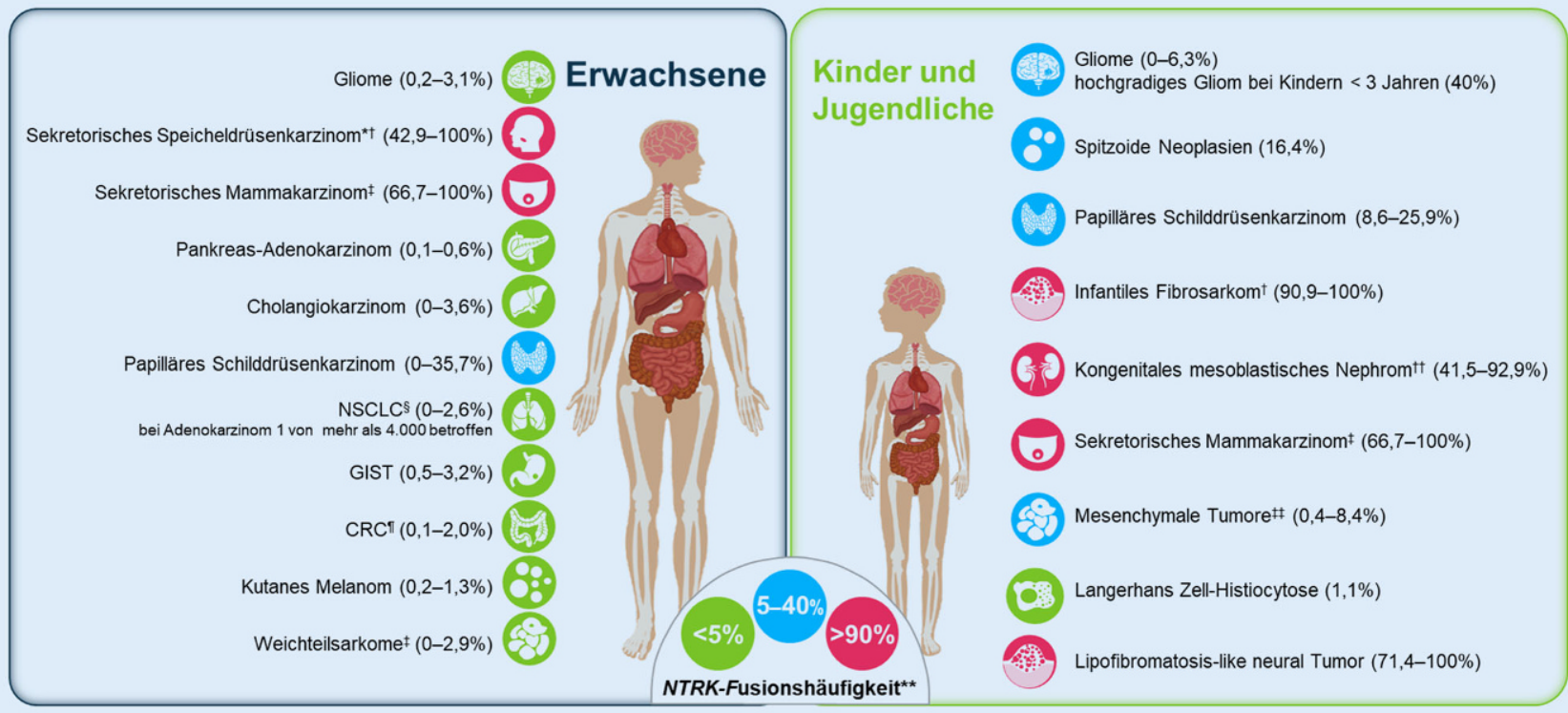

Abb. 1 \ Häufigkeiten von NTRK-Genfusionen bei Tumoren im Kindes- und Erwachsenenalter. CRCkolorektales Karzinom, GIST gastrointestinaler Stromatumor, MASC "mammary analogue secretory carcinoma", NSCLCnichtkleinzelliges Lungenkarzinom. ${ }^{*}$ Ehemals bezeichnet als MASC ${ }^{\dagger}$ NTRK-Genfusionen werden als pathognomonisch in dieser Entität betrachtet. ${ }^{\ddagger} F$ Frequenz bei Erwachsenen vs. Kindern nicht spezifiziert. ${ }^{5}$ Nur Studien mit $N \geq 200$ eingeschlossen. ${ }^{9} N u r$ Studien mit $N \geq 100$ eingeschlossen. ${ }^{\dagger+}$ Zellulärer und/oder gemischter histologischer Subtyp. ${ }^{\ddagger \neq}$ Inklusive: Fibrosarkom, solitärer fibröser Tumor, Hämangiom, Schwannom, Histiozytom, primitiver neuroektodermaler Tumor, inflammatorischer myofibroblastischer Tumor, Lipofibromatose, „primitive myxoid mesenchymal tumor of infancy“, fibröses Hamartom der Kindheit, Myofibrom/ Myofibromatose, niedrig malignes fibromyxoides Sarkom, Synovialsarkom, Spindelzell-Rhabdomyosarkom, maligner Nervenscheidentumor, Dermatofibrosarcoma protuberans (fibrosarkomatös), noduläre Fasziitis. ${ }^{* *}$ Nach Albert et al. [1], Cocco et al. [10], Gatalica et al. [20], Hyman et al. [29], Marchio et al. [42], Okamura et al. [44], Solomon et al. [57], Taylor et al. [60], Vokuhl et al. [64], Wiesner et al. [66], Wu et al. [69] und Zehir et al. [72]. Weitere Quellen im Supplement (Infobox 2)

den verfügbaren Studien mit den TRKInhibitoren wurde keine sog. Companiondiagnostik evaluiert und festgelegt. Beispielsweise erfolgte in den klinischen Untersuchungen zur Analyse der Wirksamkeit und Sicherheit von Larotrectinib der Nachweis einer TRKFusion mittels Next Generation Sequencing (NGS), Fluoreszenz-in-situHybridisierung (FISH) oder ReverseTranskriptase-Polymerase-Kettenreaktion (RT-PCR) mit unterschiedlichen Plattformen in unterschiedlichen Laboren $[5,15]$.

Zur Diagnostik von NTRK-Genfusionen stehen verschiedene Verfahren zur Verfügung (『Tab. 1). So lässt sich mithilfe der Immunhistochemie (IHC) die TRK-Expression bestimmen. Hierbei ist zu beachten, dass in bislang vorliegenden Studien dieses Verfahren mit monoklonalen TRK-Antikörpern getestet wurde. Den Antikörpern ist gemeinsam, dass sie ein C-terminales Konsensusmotiv in TRKA-C detektieren
$[1,27,42,46]$. Der zurzeit gebräuchlichste Antikörperklon ist EPR17341. Die TRKExpression ist daher nicht beweisend für das Vorliegen einer NTRK-Genfusion, da auch die Expression des WildtypTRK-Proteins nachgewiesen wird. Somit ist die Spezifität der IHC-Analyse eingeschränkt und kann zu falsch positiven Ergebnissen führen, beispielsweise in Tumoren abgeleitet von neuralem oder glattmuskulärem Gewebe mit physiologischer TRK-Expression. Auch für maligne klein-rund-und-blauzellige $\mathrm{Tu}$ moren des Kindesalters ist eine TRKExpression beschrieben, ohne dass eine Fusion zugrunde liegt [57]. Während eine Untersuchung von Hirntumoren auf NTRK-Genfusionen mithilfe der IHC aufgrund der dargestellten Konstellation nicht sinnvoll möglich ist, bietet sich das Verfahren als vergleichsweise rasch und einfach etablierbare Screeningmethode für andere Tumorentitäten dennoch an. Solomon und Kollegen berichten in ihrer Arbeit, die über 38.000 per NGS ana- lysierte Gewebeproben untersucht hat, über eine Sensitivität der NTRK-IHC von $96,2 \%$ für NTRK1-Fusionen, $100 \%$ für NTRK2-Fusionen und 79,4\% für NTRK3-Fusionen, wenn alle untersuchten Tumorentitäten kumuliert betrachtet wurden [57]. Innerhalb der untersuchten Tumorentitäten traten teils erhebliche Unterschiede zutage: Während beispielsweise für das Kolonkarzinom eine Sensitivität von $87,5 \%$ und eine Spezifität von $100 \%$ beobachtet wurden, lag diese für Mammakarzinome bei $80 \%$ bzw. $82,1 \%$ und für Speicheldrüsentumoren bei $88,9 \%$ bzw. $52 \%$. Hingegen wurde für den inflammatorischen myofibroblastären Tumor eine Sensitivität und Spezifität von jeweils $100 \%$ gemessen. Weitere Daten großer Fallkollektive, die in unabhängigen Studien erhoben wurden, sind notwendig, um die Kennwerte der IHC abschließend bewerten zu können. Zusammenfassend ist jedoch festzuhalten, dass die bisher erhobenen Daten zeigen, dass sowohl die Spezifität als auch die 
Tab. 1 Vor-und Nachteile der zur Detektion von TRK-Fusionsproteinen bzw. der NTRK-Genfusionen zur Verfügung stehenden Untersuchungsmethoden. (Mod. nach Alber et al. [1], Cocco et al. [10], Hsiao et al. [27], Kirchner et al. [31], Marchio et al. [42], Penault-Llorca et al. [46], Pfarr et al. [47], Solomon und Hechtmann [56] und Solomon et al. [57])

\begin{tabular}{|c|c|c|c|c|}
\hline & IHC & FISH & RT-PCR & NGS \\
\hline $\begin{array}{l}\text { Untersuchungs- } \\
\text { material }\end{array}$ & $\begin{array}{l}\text { Formalinfixiertes paraffinein- } \\
\text { gebettetes (FFPE) Gewebe }\end{array}$ & Frisches oder FFPE-Gewebe & $\begin{array}{l}\text { FFPE-Gewebe, schockgefrore- } \\
\text { nes Gewebe }\end{array}$ & $\begin{array}{l}\text { FFPE-Gewebe, frisches, ge- } \\
\text { frorenes, schockgefrorenes } \\
\text { Gewebe }\end{array}$ \\
\hline $\begin{array}{l}\text { Turnaroundzeit } \\
\text { (Zeit vom } \\
\text { Eingang des } \\
\text { Materials bis } \\
\text { zum Befund) }\end{array}$ & $\begin{array}{l}\text { Ergebnis in 1-2 Tagen verfüg- } \\
\text { bar }\end{array}$ & Ergebnis in 2 Tagen verfügbar & $\begin{array}{l}\text { Ergebnis in 5-10 Tagen ver- } \\
\text { fügbar }\end{array}$ & $\begin{array}{l}\text { Ergebnis nach } 2 \text { Wochen ver- } \\
\text { fügbar }\end{array}$ \\
\hline \multirow[t]{5}{*}{ Vorteile } & Schnell und kostengünstig & $\begin{array}{l}\text { Weit verbreitete und etablierte } \\
\text { Methode }\end{array}$ & $\begin{array}{l}\text { Kostengünstiges und relativ } \\
\text { schnelles Verfahren }\end{array}$ & $\begin{array}{l}\text { Kann neue } \\
\text { NTRK-Fusionspartner iden- } \\
\text { tifizieren }\end{array}$ \\
\hline & $\begin{array}{l}\text { Etabliertes Verfahren, weit } \\
\text { verbreitet }\end{array}$ & Schnell & $\begin{array}{l}\text { Zuverlässige Methode, um } \\
\text { bekannte und wiederholt } \\
\text { auftretende Genfusionen zu } \\
\text { erkennen, z.B.ETV6-NTRK3 }\end{array}$ & Gewebesparende Methode \\
\hline & $\begin{array}{l}\text { Wenig Material (Gewebe) } \\
\text { erforderlich }\end{array}$ & $\begin{array}{l}\text { Verlässliches Verfahren, um } \\
\text { bekannte und wiederholt } \\
\text { auftretende Genfusionen zu } \\
\text { erkennen, z. B. ETV6-NTRK3 }\end{array}$ & \multirow[t]{3}{*}{$\begin{array}{l}\text { 3'/5'-NTRK-Ratio: } \\
\text { Ungleichgewicht zugunsten } \\
\text { der 3'-Region als möglicher } \\
\text { Hinweis auf das Vorliegen } \\
\text { einer Genfusion }\end{array}$} & \multirow[t]{3}{*}{$\begin{array}{l}\text { Evaluierung diverser } \\
\text { Zielstrukturen in einer } \\
\text { Untersuchung }\end{array}$} \\
\hline & $\begin{array}{l}\text { Relativ hohe Sensitivität } \\
(95-100 \%, 75-96 \%) \text { und } \\
\text { Spezifität }(92 / 93-100 \%)\end{array}$ & \multirow{2}{*}{$\begin{array}{l}\text { Prinzipiell zum Nachweis auf } \\
\text { das Vorliegen von NTRK1-, } \\
\text { NTRK2-oder } \\
\text { NTRK3-Genfusionen geeignet }\end{array}$} & & \\
\hline & $\begin{array}{l}\rightarrow \text { Aber: Bislang nur in kleinen } \\
\text { Patientengruppen getestet }\end{array}$ & & & \\
\hline \multirow[t]{5}{*}{ Nachteile } & $\begin{array}{l}\text { Nicht spezifisch für } \\
\text { NTRK-Genfusionen, da sowohl } \\
\text { Wildtyp-als auch Fusionspro- } \\
\text { teine detektiert werden }\end{array}$ & $\begin{array}{l}3 \text { verschiedene Assays erfor- } \\
\text { derlich, um NTRK1-, NTRK2- } \\
\text { und NTRK3-Genfusionen zu } \\
\text { erkennen }\end{array}$ & $\begin{array}{l}\text { Zielsequenz muss bekannt } \\
\text { sein, unbekannte oder neue } \\
\text { Partner (5'-Region) werden } \\
\text { nicht ohne Weiteres entdeckt }\end{array}$ & $\begin{array}{l}\text { Eventuell Identifizierung aller } \\
\text { NTRK-Genfusionen mit kom- } \\
\text { merziellen DNA-basierten } \\
\text { Plattformen nicht möglich, } \\
\text { vor allem bei NTRK2 und } \\
\text { NTRK3-Genfusionen, da vie- } \\
\text { le Introns vorhanden }\end{array}$ \\
\hline & $\begin{array}{l}\text { Ggf. schwierige Auswertung in } \\
\text { Geweben mit physiologischer } \\
\text { TRK-Expression }\end{array}$ & $\begin{array}{l}\text { Keine Identifizierung des } \\
\text { Fusionspartners möglich, } \\
\text { sofern dieser nicht bekannt ist }\end{array}$ & \multirow{4}{*}{$\begin{array}{l}3^{\prime} / 5^{\prime} \text {-NTRK-Ratio: Sensitivität } \\
\text { abhängig von Unterschied in } \\
\text { der Expression des } \\
\text { Wildtypgens und der } \\
\text { Genfusion (nicht ausreichend } \\
\text { untersucht) }\end{array}$} & $\begin{array}{l}\text { RNA-basierte Tests stark von } \\
\text { der Qualität der RNA abhängig }\end{array}$ \\
\hline & $\begin{array}{l}\text { Vor allem TRKC } \\
\text { (NTRK3-Genfusionen) schwie- } \\
\text { rig zu diagnostizieren }\end{array}$ & \multirow[t]{3}{*}{$\begin{array}{l}\text { Nicht bekannt, ob das } \\
\text { entsprechende Produkt der } \\
\text { Genfusion exprimiert wird }\end{array}$} & & \multirow[t]{3}{*}{$\begin{array}{l}\text { Ergebnisse erst nach } 2 \text { Wochen } \\
\text { bekannt }\end{array}$} \\
\hline & $\begin{array}{l}\text { Keine Identifizierung des } \\
\text { Fusionspartners möglich }\end{array}$ & & & \\
\hline & $\begin{array}{l}\text { Keine Anwendung bei } \\
\text { ZNS-Tumoren }\end{array}$ & & & \\
\hline
\end{tabular}

Sensitivität vom analysierten Gewebetyp und der jeweiligen NTRK-Genfusion beeinflusst wird und nicht immer $100 \%$ erreicht [57], sodass in einem IHC-basierten Screeningverfahren neben falsch positiven auch falsch negative Befunde generiert werden können, dies gilt vor allem für NTRK3-Fusionen [20, 24].

Bei der FISH-Untersuchung handelt es sich um eine weit verbreitete $\mathrm{Me}$ thode zur Bestimmung chromosomaler
Translokationen [1, 10, 27, 42, 46, 56]. Sie erkennt bei der Verwendung von sog. Break-apart- oder Fusionssonden den chromosomalen Bruch eines Gens, nicht aber die Genfusion selbst inklusive des Fusionspartners. Um bekannte und wiederholt auftretende Genfusionen zu diagnostizieren, gilt die FISH generell als robustes und verlässliches Verfahren mit hoher Spezifität. Allerdings zeigen NTRK-Genfusionen mitunter nichtka- nonische Bruchpunkte, die aufgrund des Designs der jeweiligen Hybridisierungsproben nicht erkannt werden und somit $\mathrm{zu}$ einem falsch negativen Befundergebnis führen können. Ferner wird mit der Methode nicht festgestellt, ob das resultierende Genprodukt transkribiert oder exprimiert wird.

Auch die RT-PCR gilt als kostengünstiges und relativ schnelles Verfahren [1, $10,27,42,46,56,57]$. Mit diesem Ver- 
fahren lassen sich bekannte und wiederholt auftretende Genfusionen auf Transkriptebene zuverlässig erkennen. Aufgrund des großen Spektrums an NTRKGenfusionen, die seltene Fusionspartner und variable Exone involvieren, ist das Verfahren technisch jedoch nicht geeignet, um eine umfassende Fusionsanalytik durchzuführen. Insbesondere können neue Genfusionen, die neue Fusionspartner und unterschiedliche Exone umfassen, nicht identifiziert werden.

Nach aktuellem Stand der Literatur ist das fokussierte, panelbasierte NGS neben der FISH - das am besten geeignete Verfahren, um NTRK-Genfusionen in formalinfixiertem und paraffineingebettetem Probengewebe zu identifizieren [10]. Es lassen sich 2 Methoden unterscheiden: das RNA- und das DNA-basierte NGS [1, 10, 27, 42, 46, 56, 57]. Je nach eingesetztem Verfahren können damit auch neue NTRK-Fusionspartner bzw. Genfusionen entdeckt werden. Die Menge der für die Analytik verwendeten Nukleinsäuren ist assayabhängig und muss im Hinblick auf das Probenmaterial beachtet werden. Der Analysezeitraum („turnaround time“, TAT) dieser Verfahren ist abhängig von den Ressourcen und Kapazitäten der Labore sowie eingesetzten Methoden und Technologien. Die Analyse dauert aber in der Regel länger als eine IHC- oder FISH-basierte Untersuchung. Es ist wichtig festzuhalten, dass es sich sowohl bei der DNA- als auch bei der RNA-basierten NGS-PanelAnalyse um eine selektive Analyse handelt und nicht um eine Ganzgenomanalyse oder ein vollständiges Transkriptom. Dies ist relevant, da die Bruchpunkte variabel in intergenischen/intronischen $\mathrm{Be}$ reichen vorkommen, die in keinem fokussierten DNA-Assay vollständig enthalten sind. Ferner können diese Bruchpunkte in teils schwierig sequenzierbaren Regionen gelegen sein (z. B. in GC-reichen Regionen). Daher kann ein DNAAssay falsch negative Befunde erzeugen $[6,56,57]$. Solomon et al. berichten beispielsweise, dass mit dem DNA-basierten MSK-IMPACT-Panel für NTRK1-, NTRK2- und NTRK3-Genfusionen eine Sensitivität von $96,8 \%, 0 \%$ bzw. $76,9 \%$ gemessen wurde [57]. Die Sensitivität des Assays für alle NTRK-Genfusionen lag integral bei $81,1 \%$. Wahr negative Fälle wurden fast vollständig als negativ erkannt (99,86\% Spezifität). Die Kollegen beschreiben in der Arbeit, dass die meisten Fälle, die mithilfe der DNA-Analytik nicht erkannt wurden, über ein RNANGS-Verfahren identifiziert wurden. In einer anderen Studie der gleichen Institution wurden mehr als 2500 Adenokarzinome der Lunge mittels DNAbasierter NGS-Analytik untersucht und dann der Zusatznutzen eines RNA-basierten Assays analysiert [6]: In $32 \%$ der per DNA-Sequenzierung als treibernegativ erkannten Tumoren, die darüber hinaus eine eher niedrige Mutationslast aufwiesen, konnte etwa bei einem Drittel dieser Fälle in der RNA-Analytik nachträglich ein therapierbarer Treiber (Genfusion oder Met-Exon14-Skipping) identifiziert werden, darunter auch 2 Fälle mit einer NTRK3-Genfusion. Es ist aber zu beachten, dass auch die fokussierte Untersuchung der RNA, die nicht in der Lage ist, den exakten Bruchpunkt auf DNAEbene zu detektieren, wohl aber das Transkript des fusionierten Gens, mit Limitationen behaftet ist. Je nach Design des Assays werden nicht alle Genfusionen detektiert, da z. B. Primer nur bestimmte, aber nicht alle möglichen codierenden Exone erkennen, die für das jeweilige Transkript codieren [31, 47, 56, 57]. Es ist auch zu berücksichtigen, dass die RNA labiler als DNA ist und die derzeit verfügbaren Assays zur RNA-basierten Fusionsanalytik unterschiedliche RNAMengen benötigen [31, 65].

\section{Vorhandene Untersuchungs- algorithmen}

Mit dem bisherigen Wissensstand bietet es sich an, einen Diagnosealgorithmus zu entwickeln. Hierbei sind jedoch verschiedene Herausforderungen zu bewältigen. Dazu gehören etwa die relative Seltenheit der TRK-Fusionstumoren sowie die Vielzahl der potenziell betroffenen Tumorentitäten. Nicht zuletzt sind die Kosten zu berücksichtigen.

In verschiedenen Publikationen wurden Algorithmen zur Diagnose von TRKFusionsproteinen bzw. NTRK-Genfusionen vorgestellt und diskutiert. So veröffentlichte die European Society for Me- dical Oncology (ESMO) 2019 Empfehlungen zur Diagnose von NTRK-Genfusionen und der TRK-(Über-)Expression [42]. Weitere Algorithmen zur Diagnose stellten Wong et al. [67], Penault-Llorca et al. [46], Hsiao et al. [27], Pfarr et al. [47] und Naito et al. [43] vor.

\section{Erarbeitung eines Untersuchungs- algorithmus}

Wir schlagen einen modifizierten Algorithmus vor, der die unterschiedlichen Wahrscheinlichkeiten für das Vorliegen einer NTRK-Genfusion und auch die entstehenden Kosten berücksichtigt. Zudem wird einbezogen, dass Tumoren, bei denen NTRK-Genfusionen häufig vorkommen, wie das IFS oft mit anderen Therapien erfolgreich behandelt werden können.

Bei positivem Ergebnis des IHCScreenings auf TRK-Fusionstumoren müssen bestätigende Tests auf genomischer Ebene mit einer FISH/ISH oder NGS erfolgen. Mögliche Vor- und Nachteile dieser Untersuchungen sind in - Tab. 1 aufgeführt.

Der hier präsentierte Vorschlag (• Abb. 2) für einen Diagnosealgorithmus berücksichtigt die genannten Herausforderungen. Bei Tumoren mit hoher Wahrscheinlichkeit für NTRKGenfusionen, z.B. sekretorisches Speicheldrüsen- und Mammakarzinom, IFS etc. sowie bei primären Tumoren des Zentralnervensystems (ZNS) wird eine direkte molekulare Analytik empfohlen und die IHC als Zwischenschritt nicht durchgeführt. Bei Tumoren mit geringerer Wahrscheinlichkeit sind 2 Szenarien $\mathrm{zu}$ unterscheiden: Zum einen gibt es Tumorentitäten, bei denen eine NGSbasierte Fusionsanalyse bereits durchgeführt wird, z.B. beim NSCLC. Liegt eine solche Konstellation vor, ist ein vorgeschaltetes IHC-Screening überflüssig. Sollte die NGS-Analyse des NSCLC Genfusionen nicht erfassen, kommt ein sequenzielles Vorgehen mithilfe der IHC und FISH oder direkt mit einer FISHAnalyse in Betracht. Umfassende Vergleichsdatensätze liegen noch nicht vor, aber die Daten von Solomon et al. legen nahe, dass die tatsächlich negativen Fälle mit Hilfe der IHC durchweg als negativ identifiziert werden (Spezifität: 


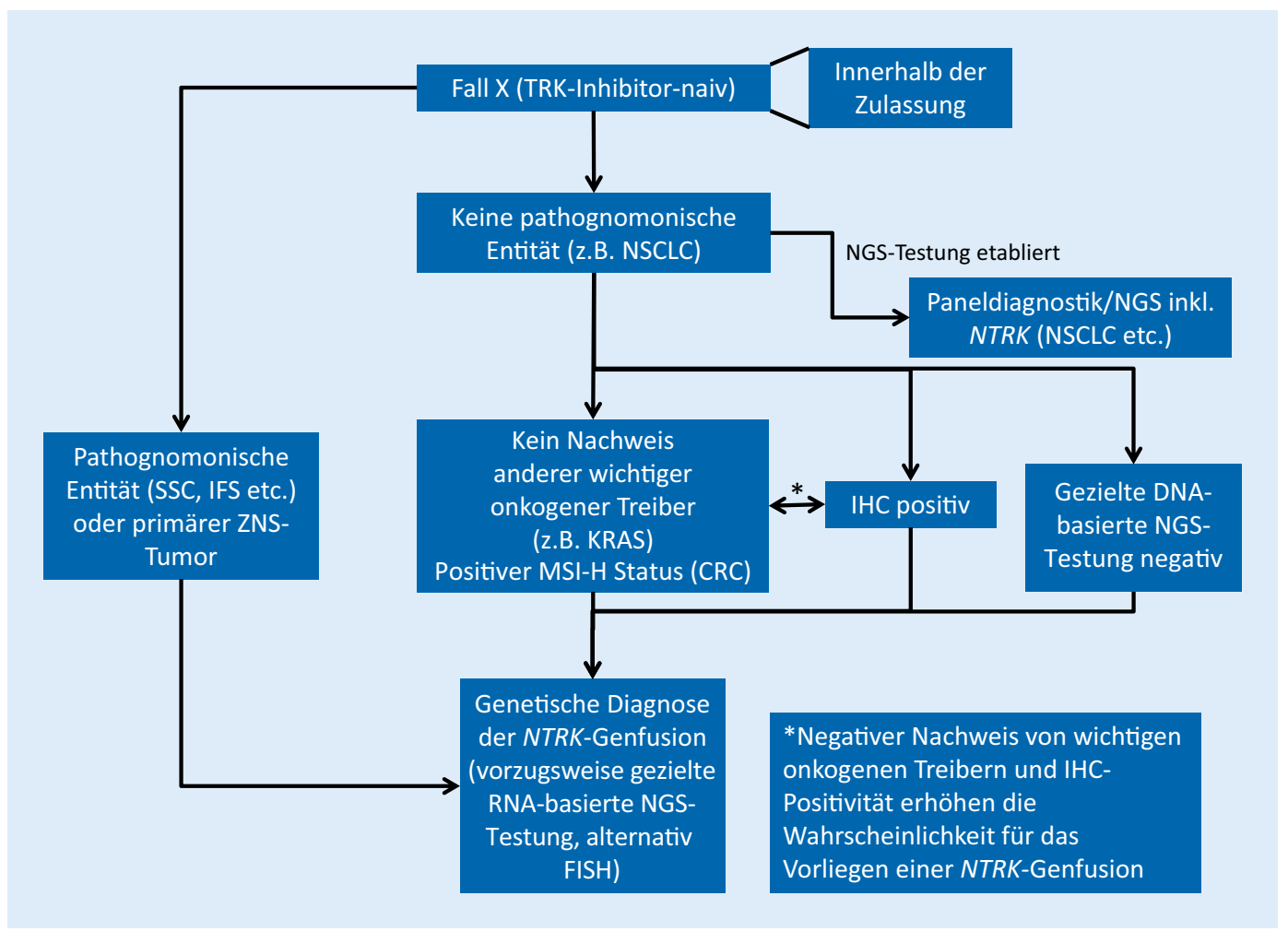

Abb. 2 A Algorithmus zur Diagnose von TRK-Fusionstumoren. Zu unterscheiden ist zwischen Tumorentitäten bei denen eine NTRK-Genfusion regelmäßig zu erwarten ist und solchen Tumortypen mit niedriger Prävalenz. Im Falle von Tumoren mit häufiger NTRK-Prävalenz ist eine typische Morphologie gegeben, die eine NTRK-Genfusion wahrscheinlich macht. In diesen Fällen ist daher eine IHC nicht sinnvoll und die Genfusion sollte direkte mit einer FISH bestätigt werden. Bei den Tumoren mit niedriger NTRK-Prävalenz ist zu differenzieren zwischen Tumorentitäten, bei denen eine NGS-basierte Analytik bereits etabliert ist. Hier kann dieses Analyseverfahren regelhaft auch für die Erkennung von NTRK-Genfusionen zum Einsatz kommen (Bsp.: NSCLC). Für andere Tumorentitäten mit niedriger NTRK-Prävalenz für die keine NGS-Analytik regelmäßig verwendet wird, ist ein Vorscreening mit Hilfe der IHC sinnvoll. Identifizierte positive Fälle müssen dann durch ein weiteres genetisches Verfahren, FISH oder NGS, bestätigt werden, da der Zulassungstext dies verlangt. Da NTRK-Genfusionen sogenannte Stammmutationen sind, die früh in der Tumorgenese auftreten, schließt das Vorhandensein dieser Fusionen einen anderen potenten onkogenen Treiber in der Regel aus. Daraus folgt umgekehrt, dass beispielsweise ein duktales Adenokarzinom des Pankreas mit einem KRAS-Wildtyp-Status die Wahrscheinlichkeit erhöht, dass eine Genfusion, bspw. eine NTRK-Genfusion, als Treibermechanismus vorliegt. Ein negatives DNA-basiertes NGS-Ergebnis im Hinblick auf eine NTRK-Genfusion kann durch ein weiteres Verfahren, wie die RNA-basierte Analytik überprüft werden, wenn der Verdacht besteht, dass das Ergebnis aus technischen Gründen negativ ausgefallen ist (siehe Text). DNA deoxyribonucleic acid (Desoxyribonukleinsäure), FISH Fluoreszenz-in-situ-Hybridisierung, IHC Immunhistochemie, IFS infantiles Fibrosarkom, NGS Next Generation Sequencing, NSCLC nicht-kleinzelliges Lungenkarzinom, NTRK neurotrophe Tyrosin-Rezeptor-Kinase, RNA ribonucleic acid (Ribonukleinsäure), SSC secretory salivary gland carcinoma (sekretorisches Speicheldrüsenkarzinom), TRK Tropomyosin-Rezeptor-Kinase, ZNS Zentralnervensystem

$100 \%$ ), während die Sensitivität der IHC in der Studie nur bei ca. $87 \%$ lag, sodass positive Fälle möglicherweise in der IHC-Analyse nicht erkannt werden [57]. Diagnostisch hilfreich ist in dem Kontext auch das Konzept des einander ausschließenden Treiberveränderungen: Ein NSCLC ohne Nachweis einer typischen Treiberveränderung (EGFR, ALK, ROS, RET, BRAF, KRAS etc.) erhöht die Prätestwahrscheinlichkeit für die Detektion eines anderen Treibers inklusive der NTRK-Genfusionen.

Zum anderen gibt es zahlreiche Tumorentitäten, bei denen eine umfassen- de Genfusionsanalytik derzeit kein Standard ist. Hier sollten aus ökonomischen Gesichtspunkten In-situ-Verfahren wie die IHC (mit oben genannten Einschränkungen) oder FISH zur Vorselektion berücksichtigt werden. Für die Fallauswahl sollten neben dem Stadium und den noch zur Verfügung stehenden klinischen Therapiemöglichkeiten auch z.B. der fehlende Nachweis anderer typischer Treibermutationen (z. B. duktales Adenokarzinom mit KRAS-Wildtyp-Status, 4fach negativer GIST [gastrointestinaler Stromatumor]) berücksichtigt werden. Kürzlich publizierte Daten legen nahe, dass
Kolonkarzinome mit MSI-H-Status und fehlendem Nachweis klassischer onkogener Treiber vermehrt NTRK-Fusionen aufweisen [7, 48]. Es ist zu erwarten, dass sich mit wachsendem wissenschaftlichem Erkenntnisgewinn im Laufe der Zeit das Spektrum molekularer Profile, die möglicherweise helfen, NTRK-positive Tumoren zu identifizieren, erweitert. Klinische Parameter, wie z. B. junge Patienten, keine regelmäßige Exposition zu typischen externen Noxen, können ebenfalls hilfreich sein. Auch hier ist zu erwarten, dass der wissenschaftliche Kenntnisstand wachsen wird. Grundsätzlich muss 
ein positives IHC-Ergebnis nachfolgend durch ein anderes Nachweisverfahren, das die zugrunde liegende Translokation/ Genfusion erkennt (z. B. FISH oder NGS) bestätigt werden. Das Ergebnis der IHC allein ist aufgrund der weiter oben dargestellten Konstellation nicht hinreichend.

$\mathrm{Zu}$ beachten ist auch, dass, wie in - Abb. 2 dargestellt, aufgrund der weiter oben dargestellten Konstellation ein negatives NTRK-Fusionsergebnis mittels eines DNA-basierten NGS-Panels auch falsch negativ sein kann, sodass bei entsprechender Plausibilitätsanalyse (beispielsweise junger Patient ohne detektierten Treiber auf DNA-Ebene) eine ergänzende RNA-Analyse zur Fusionsdetektion erwogen werden kann [6].

Für die pädiatrische Onkologie ist eine zentrale referenzpathologische Diagnostik im Rahmen der verschiedenen Therapieoptimierungsstudien solider $\mathrm{Tu}$ moren der Gesellschaft für Pädiatrische Onkologie und Hämatologie (GPOH) etabliert. In diesem Rahmen ist auch eine panelbasierte NGS-Analytik für pädiatrische Sarkome aufgebaut worden. Die INFORM-Plattform bietet für Hochrisikoerkrankungen im Rezidivfall, aber auch für bestimmte Hochrisikoerkrankungen im Rahmen der Primärdiagnose (z. B. metastasierte Rhabdomyosarkome und hochmaligne Gliome [HGG]) umfassende molekulare Analysen an (WES, lcWGS, RNAseq und DNA-Methylierung) [63]. Für niedrigmaligne Gliome (LGG) steht bundesweit die LOGGICCore-Plattform zur Verfügung, die eine panelbasierte NGS-Analytik und eine RNA-Sequenzierung in Fällen anbietet, bei denen die Treiberalteration mittels Panel nicht identifiziert wurde [30, 40, $41,58]$.

\section{Klinische Testsituation und Testzeiträume}

Für die Testung sollte möglichst aktuelles Gewebe verwendet werden. Wenn dies nicht der Fall ist, ist der Rückgriff auf älteres Archivmaterial möglich, da eine NTRK-Genfusion in der Regel eine sog. Stammmutation (,truncal mutation“) ist, die früh im Rahmen der Tumorevolution auftritt und tumortreibend ist. Eine
Ausnahme sind sekundäre NTRK-Genfusionen, die als Resistenzmechanismus im Rahmen einer Tyrosinkinaseinhibitortherapie beschrieben worden sind [70]. Der Testzeitpunkt muss sich an den aktuellen, in den entitätsspezifischen Leitlinien festgelegten, stadienabhängigen Therapieverfahren orientieren und den Zulassungstext im Hinblick auf den zu untersuchenden klinischen Fall berücksichtigen $[5,13,21]$ :

1. lokal fortgeschrittene, metastasierte Tumoren oder Tumoren, bei denen chirurgische Resektionen mutmaßlich zu einer hohen Morbidität führen oder

2. es keine zufriedenstellenden Therapieoptionen gibt.

Die Zulassung erstreckt sich auf alle soliden Tumorentitäten.

Derzeit gibt es keine internationalen Empfehlungen oder Leitlinien, die die Turnaroundzeiten (TAT), definiert als Zeitraum zwischen Erhalt des Gewebes bis zur Versendung des Befundes, für die molekulare Diagnostik in Tumorentitäten außer dem NSCLC abschließend festlegt. Die internationale Leitlinie zur molekularen Testung von Lungenkrebspatienten definiert einen Zeitraum von 10 Werktagen, der sicherlich einen Orientierungspunkt darstellt [38]. Aus Sicht der Autoren ist daher ein Testergebnis innerhalb von etwa 10 Werktagen anzustreben. Hierbei ist jedoch anzumerken, dass die Menge und Qualität des Gewebes und der Nukleinsäuren die TAT beeinflusst und im Einzelfall längere TAT möglich sein können.

\section{Wie können TRK-Fusions- tumoren behandelt werden?}

Tumoren mit NTRK-Genfusionen bzw. TRK-Fusionstumoren können seit kurzem mit TRK-Inhibitoren behandelt werden. Derzeit liegt für einen TRKInhibitor (Larotrectinib) eine Zulassung in der Europäischen Union vor (s. Abschn. „Larotrectinib“). TRK-Inhibitoren sind für die Therapie von Tumoren mit somatischen NTRK-Punktmutationen, NTRK1-Splicevarianten oder einer TRK-Überexpression des Wildtypproteins nicht zugelassen bzw. geeig- net. Zur Beurteilung der Wirksamkeit von TRK-Inhibitoren wie Larotrectinib bei NTRK-Mutationen und NTRKGenamplifikationen liegen bislang keine ausreichenden Daten vor, die einen therapeutischen Einsatz rechtfertigen würden [25].

\section{TRK-Inhibitoren}

TRK-Inhibitoren sind Tyrosinkinaseinhibitoren aus der Klasse der „small molecules". Derzeit befinden sich mehrere in der Entwicklung bzw. sind bereits zugelassen. Dazu gehört Larotrectinib, ein hochselektiver und hochpotenter Inhibitor aller 3 TRK-Proteine (Pan-TRKInhibitor), der praktisch keine Mitglieder anderer Kinasefamilien hemmt [15]. Ein weiterer Vertreter ist Entrectinib, ein Pan-TRK-Inhibitor, der auch Fusionsproteine von ROS1 (Protoonkogen-Protein-Tyrosinkinase) und ALK inhibiert [10]. Weiterhin hemmt Entrectinib Januskinase 2 und TNK2 („tyrosine kinase non receptor 2") [21]. Die Zulassung wurde als TRK- und ROS1-Inhibitor beantragt. Weitere TRK-Inhibitoren sind Selitrectinib und Repotrectinib, die sich gegenwärtig in der klinischen Prüfung befinden. Ersterer ist ein TRK-Inhibitor der nächsten Generation, der bei Resistenzmutationen gegenüber Larotrectinib oder Entrectinib eingesetzt werden kann [10]. Letzterer gilt als TRK-, ROS1- und ALK-Inhibitor der zweiten Generation, der bei Resistenzmutationen gegenüber Entrectinib (bei TRK- oder ROS1-Resistenz) oder Larotrectinib (bei TRK-Resistenz) wirksam sein kann [10].

\section{Wirksamkeit von TRK-Inhibitoren}

\section{Larotrectinib}

Larotrectinib ist weltweit bereits in mehr als 30 Ländern zugelassen, darunter in den USA [54] und in der Europäischen Union (EU) [5]. Die Anwendung kann nach dem Zulassungstext als orale Monotherapie zur Behandlung von erwachsenen und pädiatrischen Patienten mit soliden Tumoren mit einer NTRK-Genfusion [5] erfolgen,

- bei denen eine lokal fortgeschrittene oder metastasierte Erkrankung vorliegt oder eine Erkrankung, bei der 
eine chirurgische Resektion wahrscheinlich zu schwerer Morbidität führt und

- für die keine zufriedenstellenden Therapieoptionen zur Verfügung stehen.

Die Zulassung für Larotrectinib in der EU beruht auf den Ergebnissen gepoolter Analysen [26, 29, 35] von Patienten mit TRK-Fusionstumoren aus einer Phase-1-Studie mit Erwachsenen [25], einer Phase-1/2-Studie mit Kindern und Heranwachsenden ( $\leq 21$ Jahre; SCOUT) [33] und einer Phase-2-Studie mit Heranwachsenden ( $\geq 12$ Jahre) und Erwachsenen (NAVIGATE), die mit Larotrectinib behandelt wurden. Die Patienten wiesen insgesamt 25 verschiedene $\mathrm{Tu}$ morentitäten auf: IFS, andere Sarkomentitäten, Melanome, Tumoren der Schilddrüse, der Lunge, des Dickdarms, der Speicheldrüsen sowie primäre ZNS-Tumoren. Etwa die Hälfte der Patienten hatte keine oder nur eine systemische Vortherapie erhalten, die andere Hälfte 2 oder mehr Vortherapien (Tab. S1). Die Beurteilung des Tumoransprechens erfolgte nach den RECIST-v1.1-Kriterien bzw. bei ZNS-Tumoren/Filiae nach RANO-Kriterien.

Wirksamkeit von Larotrectinib. In der bislang letzten Auswertung lag die Altersspanne der Effektivitätskohorte $(n=159)$ zwischen $<0,1$ und 84 Jahren (Tab. S1; $[26,29])$. Die aus den Dosisfindungsstudien resultierende Dosierung betrug $100 \mathrm{mg}$ zweimal täglich für Erwachsene bzw. $100 \mathrm{mg} / \mathrm{m}^{2}$ Körperoberfläche (jedoch nicht mehr als $100 \mathrm{mg}$ ) zweimal täglich bei Kindern und Jugendlichen, die in Form von Kapseln oder einer Lösung eingenommen werden konnten. Die Prüfarzt-bestimmte objektive Ansprechrate (ORR, primärer Endpunkt) betrug 79\%, das mediane progressionsfreie Überleben (PFS) 28,3 Monate und das mediane Gesamtüberleben (OS) 44,4 Monate $[26,29]$. Weitere Ergebnisse sind in der Tab. S2 zusammengefasst. Zum Zeitpunkt der Analyse setzten $74 \%$ aller Patienten die Therapie fort.

Die Wirksamkeit von Larotrectinib bei primären oder sekundären TRK-Fusionstumoren des ZNS wurde ebenfalls berichtet $[17,26]$. Eingeschlossen waren 18 Patienten mit primären Hirntumoren und 12 Patienten mit Hirnmetastasen. Unter den Patienten mit primären Hirntumoren hatten 15 (83\%) mindestens eine systemische Vortherapie erhalten, 13 waren zuvor operiert oder bestrahlt worden. In dieser Gruppe lag das mediane Alter bei 10 Jahren (Spanne 1 Jahr-79 Jahre). Die ORR betrug bei den 14 Patienten mit analysierbaren Daten zum Auswertungszeitpunkt $36 \%$ (Tab. S2). Die Therapie wurde in den meisten Fällen zu diesem Zeitpunkt noch fortgeführt. Patienten mit Hirnmetastasen wiesen eine ORR von $75 \%$ auf (Tab. S2).

\section{Entrectinib}

Entrectinib ist in den USA schon sowohl zur Therapie von Erwachsenen mit ROS1-positivem NSCLC als auch zur Therapie von erwachsenen und pädiatrischen Patienten ab 12 Jahren mit soliden Tumoren zugelassen, die [21]

- eine NTRK-Genfusion ohne eine erworbene Resistenzmutation aufweisen und

- metastasiert sind oder bei denen eine chirurgische Resektion wahrscheinlich zu schwerer Morbidität führt, und

- nach einer Therapie progredient waren oder für die keine zufriedenstellende alternative Therapie verfügbar ist.

Entrectinib steht als Kapsel zur Verfügung [21]. Die empfohlene Dosierung beträgt für Erwachsene einmal täglich $600 \mathrm{mg}$ und für Heranwachsende $\mathrm{ab}$ 12 Jahren abhängig von der Körperoberfläche (KOF) einmal täglich $600 \mathrm{mg}$ (KOF >1,5 m²), 500 mg (KOF 1,1-1,5 m²) oder $400 \mathrm{mg}$ (KOF 0,91-1,10 m²).

Die Wirksamkeit und Verträglichkeit von Entrectinib wurde in verschiedenen Studien bei Kindern, Heranwachsenden und Erwachsenen mit TRK-Fusionstumoren sowie mit ROS1- und ALKpositivem NSCLC evaluiert. Dazu gehören die Phase-1-Studien ALKA-372-001 und STARTRK-1, die Phase-2-Studie STARTRK-2 und die Phase-1/1b-Studie STARTRK-NG [39].
Wirksamkeit von Entrectinib. In eine gepoolte Analyse wurden insgesamt 54 erwachsene Patienten mit TRK-Fusionstumoren aus der ALKA-372-001- $(n=1)$, STARTRK-1- $(n=2)$ und STARTRK-2Studie $(n=51)$ eingeschlossen $[12,14,50$, 55]. Die 3 häufigsten Tumorarten waren Sarkome (24\%), NSCLC (19\%) und das sekretorische Speicheldrüsenkarzinom (13\%) [12, 14]. Fast $40 \%$ der Teilnehmer hatten keine und ca. $20 \%$ nur eine systemische Vortherapie, weitere $40 \% 2$ oder mehr Vortherapien erhalten (Tab. S3). Das mediane Alter der Patienten mit TRK-Fusionstumoren betrug 57,5 Jahre (Tab. S3). Primäre Endpunkte der gepoolten Analyse waren die ORR und die Dauer des Ansprechens (DOR, beide unabhängig bestimmt per RECIST v1.1) [12]. Die ORR betrug in der Gesamtpopulation 59,3\%, das mediane PFS 11,2 Monate und das mediane OS 20,9 Monate [50]. Weitere Ergebnisse zu Wirksamkeitsparametern sind in der Tab. S4 zusammengefasst. Bei 12 Patienten mit TRK-Fusionstumoren waren $\mathrm{zu}$ Studienbeginn ZNS-Metastasen nachweisbar [50, 55]. Bei diesen Patienten betrug die ORR 58,3\% (Tab. S4).

Daten zur Verträglichkeit von Larotrectinib und Entrectinib haben wir im elektronischen Supplement (S-Infobox 1) dargestellt.

\section{TRK-Inhibitoren: Anwendung bei Kindern und Heranwachsenden}

Sowohl für Larotrectinib als auch für Entrectinib liegen in separaten Auswertungen erhobene Daten zur Wirksamkeit und Verträglichkeit bei Kindern und Heranwachsenden vor. So gibt es eine Analyse zu Larotrectinib in der Therapie von 38 jungen Patienten ( $<18$ Jahre) mit lokal fortgeschrittenen oder metastasierten TRK-Fusionstumoren. Patienten mit primärenZNS-Tumoren waren hier nicht eingeschlossen [62]. Das Alter der Betroffenen reichte von 0,1 bis 14 Jahren, im Median lag es bei 2,3 Jahren. Fast die Hälfte der Teilnehmer wies ein IFS (47\%) auf, weitere Krebserkrankungen waren andere Weichgewebesarkome (42\%), Schilddrüsenkarzinome (5\%), CMN (3\%) und Melanome (3\%). Vor Studienbeginn hatten $32 \%$ keine, $53 \% 1-2$ und $16 \%$ min- 
destens 3 systemische Vortherapien erhalten. Die durch den Prüfarzt bestimmte ORR betrug $94 \%$. Zum Zeitpunkt des Datenschnitts und der anschließenden Analyse (30.07.2018) waren die mediane DOR, das mediane PFS und das mediane OS noch nicht erreicht. Von den Patienten wurden $87 \%$ (33 von 38) zum Auswertungszeitpunkt mit Larotrectinib weiterbehandelt oder konnten sich einer kurativen chirurgischen Therapie unterziehen.

Auftretende unerwünschte Ereignisse (UE) wie erhöhte ALT (43\%), Erbrechen (41\%), erhöhte Aspartat-Aminotransferase-Werte (AST, 39\%), Diarrhö (34\%) sowie Husten und Neutropenie (je $32 \%$ ) waren überwiegend von Grad 1 oder Grad 2 [62]. Zu den häufigsten Grad-3-UEs zählten Neutropenie (13\%) und Gewichtszunahme (9\%). Grad-4-UEs waren mit je $2 \%$ eine reduzierte Neutrophilenzahl und Fieber.

In der STARTRK-NG-Studie wurde die Therapie mit Entrectinib - in den USA zugelassen ab 12 Jahren - bei Kindern und Heranwachsenden evaluiert $[21,49]$. Eingeschlossen waren 29 Patienten im Alter von 0-20 Jahren (Median: 7 Jahre). Bei 13 Patienten mit hochgradigen Gliomen, Sarkomen, embryonalen ZNS-Tumoren, Neuroblastomen oder Melanomen ließen sich NTRK- $(n=7)$, ROS1- $(n=3)$ oder ALK-Genfusionen $(n=3)$ feststellen. Zum Zeitpunkt der Analyse (31.10.2018) lebten alle Patienten mit NTRK-Genfusions-, ROS1oder ALK-positiven Tumoren, von denen $75 \%$ weiterhin Entrectinib erhielten. Eine komplette Remission zeigte in der Gruppe mit TRK-Fusionstumoren ein Patient und bei 4 Patienten wurde eine partielle Remission erzielt. Insgesamt war zum Auswertungszeitpunkt die mediane DOR noch nicht erreicht, sie lag zwischen 1,8 und 15,7 Monaten. Die häufigsten UEs aller Grade waren Anämie und erhöhte Kreatininkonzentration im Blut (je $41 \%$ ), erhöhte ALT, erhöhte AST und Übelkeit (je $35 \%$ ). Grad-3/4-UEs traten bei insgesamt $10 \%$ der Patienten auf, wobei die Neutropenie mit 5 Fällen (17\%) am häufigsten vorkam.

Sicherheitsdaten unter Langzeitexposition von TRK-Inhibitoren liegen noch nicht vor, vor allem keine Daten zu spezi- fisch pädiatrischen unerwünschten Wirkungen, wie z. B. ein Einfluss auf das Körperwachstum, die Pubertät oder die neurokognitive Entwicklung.

Generell ist jedoch zu berücksichtigen, dass sowohl bei der CMN als auch beim IFS der chirurgische Eingriff die wesentliche Therapieoption darstellt [22, 23, 34]. Bei fortgeschrittenen Tumoren kann eine Chemotherapie mit einem relativ geringen Risiko für Spätfolgen sinnvoll sein [45]. Daher wird der Einsatz von TRK-Inhibitoren beim IFS in der Erstlinie außerhalb von Studien zurzeit nicht empfohlen.

\section{Beginn einer Therapie mit TRK-Inhibitoren}

Generell sieht der Zulassungstext für Larotrectinib und der wahrscheinlich ähnlich lautende für Entrectinib den Einsatz der Medikamente in späteren Therapielinien vor. Jedoch hat die European Medicines Agency (EMA) in ihrem „European Public Assessment Report“ (EPAR) für Larotrectinib festgestellt, dass prinzipiell auch ein Einsatz in früheren Therapielinien möglich ist, die Voraussetzungen hierfür sind, dass keine Standardtherapien existieren, oder, selbst wenn Therapien empfohlen werden, diese keinen nachgewiesenen und relevanten klinischen Vorteil zeigen [18].

Das Ziel einer Behandlung in diesem Krankheitsstadium ist die Reduktion von Symptomen und die Verlängerung der Überlebenszeit bei möglichst guter Lebensqualität. Patienten, die der Indikation von Larotrectinib entsprechen, haben also keine anderen Therapieoptionen mehr, die ein positives Nutzen-RisikoVerhältnis erwarten lassen oder haben eine Chance auf Heilung nur durch mutilierende Operationen.

Die Indikation kann auch gegeben sein, wenn etwa noch vorhandene Salvage-Therapien aufgrund von zu erwartenden Toxizitäten oder Komorbiditäten, auch im Hinblick auf eine adäquate Lebensqualität, nicht (mehr) durchführbar sind. Der individuellen Abwägung durch den behandelnden Arzt, ob es noch Therapieoptionen gibt, die in der Bewertung des Nutzen-Risiko-Verhältnisses besser abschneiden als durch den Einsatz von
TRK-Inhibitoren nach vorhandener Studienlage $\mathrm{zu}$ erwarten ist, kommt somit die entscheidende Bedeutung zu. Für diese Abwägung sind insbesondere die bekannten Daten zur ORR, zum PFS und der Verträglichkeit fundamental.

Es existieren bislang keine Daten, die Klarheit im Hinblick auf die notwendige Therapiedauer mit TRK-Inhibitoren liefern. In den gegenwärtigen Studien erfolgte eine Therapie bis zum Progress (in einzelnen Fällen auch darüber hinaus), dem Abbruch der Studie durch den Patienten oder dem Auftreten einer dosislimitierenden Toxizität $[5,15,26,29]$. Ob und wie lange eine Therapie über eine komplette Remission hinaus notwendig ist, ist gegenwärtig unklar, genauso wie die Fragestellung, wie oft ein erneuter Einsatz eines TRK-Inhibitors bei einem Tumorprogress nach vorangegangenem Absetzen der Therapie wirksam ist (sog. Rechallenge). Zusammenfassend kann festgehalten werden, dass die Therapiedauer unklar ist, vor dem Hintergrund und dem Verständnis anderer tyrosinkinasetherapeutischer Konzepte scheint aber derzeit i.d. R. eine Therapie bis zum Progress oder bis zur Therapieunverträglichkeit gerechtfertigt. Sicherlich ist dies besonders im pädiatrischen Setting individuell zu diskutieren.

\section{Entwicklung von Resistenzen gegenüber TRK-Inhibitoren}

Es ist beschrieben, dass fusionspositive Tumoren unter Therapie mit TRK-Inhibitoren Resistenzen entwickeln können [16]. Zugrunde liegende Mechanismen können zum einen sog. On-target-Alterationen sein. Dabei handelt es sich um Mutationen oder Amplifikationen, die in der Genfusion vorkommen [53], u. a. Basensubstitutionen in der NTRKKinasedomäne (Gatekeeper-Mutationen) wie $\mathrm{F} 589 \mathrm{~L}$ in TRKA, F633L in TRKB und F617L in TRKC, SolventFront-Mutationen wie G595R in TRKA, G639R in TRKB und G623R in TRKC sowie $\mathrm{x}$-DFG-motif-Mutationen wie G667C in TRKA, G709C in TRKB und G696A in TRKC [10, 28]. Es können aber auch sog. Off-target-Alterationen zur Resistenzentwicklung beitragen, z. B. mittels Aktivierung anderer, durch die 
Substanzen nicht gehemmter Signalwege („Bypass-Signalweg“) [53]. Bei einer Aktivierung des MAPK-Signalwegs als Bypass-Signalweg weisen erste präklinische Daten darauf hin, dass eine Kombination aus einem MEK- und einem TRK-Inhibitor wirksam sein könnte [11].

Zweitgenerations-TRK-Inhibitoren sind selbst bei bestimmten On-targetAlterationen wirksam [16]. Ein Vertreter ist Selitrectinib (BAY 2731954), das oral verfügbar ist und in präklinischen Untersuchungen Aktivität gegen erworbene Solvent-Front-, Gatekeeperund $\mathrm{x}$-DFG-motif-Mutationen zeigte. Selitrectinib wird in einer Phase-I/IIStudie (NCT03215511, LOXO-EXT17005) und in Single-Patient-Protokollen geprüft [28]. Insgesamt wurden 31 Patienten, darunter 7 pädiatrische Patienten, mit TRK-Fusionstumoren wie Sarkomen, GIST, Pankreastumoren, sekretorischen Speicheldrüsenkarzinomen oder Glioblastomen mit einem medianen Alter von 37 Jahren (Spanne 1,25-72 Jahre) behandelt. Alle Patienten waren entweder intolerant gegenüber oder progredient unter einer vorherigen TRK-Inhibitor-Therapie. Bei einer Dosierung von maximal $100 \mathrm{mg}$ zweimal täglich erwies sich Selitrectinib als verträglich. Es zeigten sich erste Hinweise auf Wirksamkeit gegen Tumoren mit erworbenen Resistenzmutationen in der Kinasedomäne [16].

Ein weiterer Vertreter ist Repotrectinib (TPX-0005). Die Substanz wird derzeit in der Phase-I/II-Studie TRIDENT-1 (NCT03093116) überprüft [10]. Eingeschlossen werden können u.a. Patienten mit fortgeschrittenen soliden Tumoren, inklusive primären ZNS-Tumoren, mit vorheriger TRK-Inhibitor-Therapie [9].

\section{Fazit für die Praxis}

\footnotetext{
- NTRK-Genfusionen sind starke onkogene Treiber, die tumorentitätenübergreifend vorkommen.

- Die Wirksamkeit und Verträglichkeit der TRK-Inhibitoren Larotrectinib und Entrectinib wurden in PhaseI- und Phase-II-Studien gezeigt. Die bisherigen Daten legen nahe, dass eine Langzeitgabe möglich ist.
}

- Entrectinib erwies sich ebenfalls als wirksam bei TRK-Fusionstumoren, aber auch bei ROS1-positiven Tumoren. Die Substanz war ebenfalls gut verträglich und hatte ein gut zu beherrschendes Sicherheitsprofil.

- Es fehlen derzeit Informationen zu den möglichen Langzeitfolgen einer Therapie mit TRK-Inhibitoren.

- Die geringe Inzidenz der TRK-Fusionstumoren stellt die Diagnostik vor Herausforderungen. Zum einen sollten alle Patienten, die TRK-Fusionstumoren aufweisen, eine wirksame Therapie erhalten können, zum anderen muss der Diagnostikansatz die Epidemiologie, die jeweilige Tumorhistologie sowie die Ausstattung und Ressourcen des pathologischen Instituts berücksichtigen.

- Mit dem hier vorgestellten Diagnosealgorithmus möchten wir einen praktikablen und zuverlässigen Weg für die Diagnose von TRK-Fusionstumoren vorschlagen.

\section{Korrespondenzadresse}

\section{Prof. Dr. Albrecht Stenzinger}

Allgemeine Pathologie und pathologische Anatomie, Pathologisches Institut, Universitätsklinikum Heidelberg Im Neuenheimer Feld 224, 69120 Heidelberg, Deutschland

Albrecht.Stenzinger@med.uni-heidelberg.de

Danksagung. Das Medical Writing wurde durch die dkg-web GmbH (Dr. Anne-Kristin Schulze) unterstützt und durch die Bayer Vital GmbH gefördert.

Author Contribution. Literaturrecherche, Datenanalyse und Manuskripterstellung. Epidemiologie: F. Länger, L. C. Heukamp, M. Hummel, C. Vokuhl, W. Weichert, P. Schirmacher, T. T. W. Seufferlein, A. Stenzinger, B. Wörmann, SJ, C. van Tilburg, S. Bielack, B. Wörmann, C. Bokemeyer. Genetik und Biologie: F. Länger, L.C. Heukamp, M. Hummel, C. Vokuhl, W. Weichert, P. Schirmacher, T. T. W. Seufferlein, A. Stenzinger, B. Wörmann, S. Loges. Pathologie und molekularpathologische Testung: F. Länger, L. C. Heukamp, M. Hummel, C. Vokuhl, W. Weichert, P. Schirmacher, C. van Tilburg, T. T. W. Seufferlein, A. Stenzinger. Studiendaten zu adulten Patienten: G. Tabatabai, F. Griesinger, F. Overkamp, P. Reichardt, C. B. Westphalen, C. Bokemeyer, P. Ivanyi, S. Loges, B. Wörmann, T. T. W. Seufferlein. Studiendaten zu pädiatrischen Patienten: C. van Tilburg, N. Graf, T. Klingebiel, S. Hettmer, M. Scheer, S. Bielack. Die initiale Version des Manuskripts wurde von T. T. W. Seufferlein, S. Bielack und A. Stenzinger erstellt. Alle Autoren haben an der Erstellung des finalen Manuskripts mitgewirkt und der Publikation zugestimmt.
Funding. Open Access funding enabled and organized by Projekt DEAL.

\section{Einhaltung ethischer Richtlinien}

Interessenkonflikt. A. Stenzinger hat persönliche Honorare von AstraZeneca, Zuwendungen und persönliche Honorare von Bayer, Zuwendungen und persönliche Honorare von BMS, persönliche Honorare von MSD, persönliche Honorare von Takeda, persönliche Honorare von Seattle Genetics, Zuwendungen von Chugai, persönliche Honorare von Novartis, persönliche Honorare von Illumina, persönliche Honorare von Thermo Fisher und persönliche Honorare von Eli Lily unabhängig von der eingereichten Arbeit erhalten. C. van Tilburg hat persönliche Honorare von Bayer und Novartis unabhängig von der eingereichten Arbeit erhalten. G. Tabatabai hat persönliche Honorare von Bayer im Rahmen der Studiendurchführung sowie Zuwendungen und persönliche Honorare von AbbVie, Zuwendungen und persönliche Honorare von Medac, Zuwendungen und persönliche Honorare von Novocure und Zuwendungen von Roche Diagnostics unabhängig von der eingereichten Arbeit erhalten. F. Länger hat persönliche Honorare von der BAYER Vital GmbH im Rahmen der Studiendurchführung sowie persönliche Honorare von Hoffmann-La Roche, AstraZeneca, Bristol-Myers Squibb und Merck \& Co. unabhängig von der eingereichten Arbeit erhalten. F. Griesinger hat persönliche Honorare von Bayer und Roche im Rahmen der Studiendurchführung sowie Zuwendungen und persönliche Honorare von Astra Zeneca, Zuwendungen und persönliche Honorare von Boehringer Ingelheim, persönliche Honorare von Abbvie, Zuwendungen und persönliche Honorare von Lilly, Zuwendungen und persönliche Honorare von Novartis, Zuwendungen und persönliche Honorare von Pfizer, Zuwendungen und persönliche Honorare von BMS, Zuwendungen und persönliche Honorare von MSD, Zuwendungen und persönliche Honorare von Amgen, Zuwendungen und persönliche Honorare von Takeda, Zuwendungen und persönliche Honorare von Siemens, persönliche Honorare von Guardant Health und persönliche Honorare von Tesaro unabhängig von der eingereichten Arbeit erhalten. S. MerkelbachBruse hat persönliche Honorare von Pfizer, Novartis, Roche, Bayer und AstraZeneca, persönliche Honorare von und nichtfinanzielle Unterstützung von BMS sowie Zuwendungen und nichtfinanzielle Unterstützung von Janssen unabhängig von der eingereichten Arbeit erhalten. F. Overkamp hat Honorare von Amgen, AstraZeneca, Bayer, Beiersdorf, BMS, Boehringer, Chugai, Celgene, Eisai, Gilead, Hexal, lomedico, Ipsen, Janssen, Merck, MSD, Novartis, Novonordisc, Riemser, Servier und Shire erhalten, Beratungs- bzw. Gutachtertätigkeit für Amgen, Bayer, BMS, Boehringer, Cellex, ClinSol, Gilead, Hexal, lomedico, MSD, Novartis, Riemser, Roche, Tesaro und Teva, Besitz von Geschäftsanteilen, Aktien oder Fonds der OncoConsult Overkamp GmbH, onkowissen.de $\mathrm{GmbH}$. P. Reichardt Zuwendungen und persönliche Honorare von Novartis sowie persönliche Honorare von Pfizer, Bayer, PharmaMar, Lilly, Amgen, Clinigen, Roche und Deciphera unabhängig von der eingereichten Arbeit erhalten. M. Scheer hat persönliche Honorare von Bayer im Rahmen der Studiendurchführung sowie persönliche Honorare von Bayer und Eli Lilly unabhängig von der eingereichten Arbeit erhalten. W. Weichert hat persönliche Honorare von Roche, MSD, BMS, AstraZeneca, Pfizer, Merck, Lilly, Boehringer, Novartis, Takeda, Amgen und Astellas, Zuwendungen von Roche, MSD, BMS und Bruker unabhängig von der eingereichten Arbeit erhalten. 
C. B. Westphalen hat persönliche Honorare und Vortragshonorare, Erstattungen für Kosten von Reisen und Unterkunft sowie Honorare für die Teilnahme an Advisory Boards von Bayer, Celgene, Ipsen, MedScape, Rafael Pharmaceuticals, RedHill, Roche, Servier, Shire/ Baxalta und Taiho sowie ein Forschungsstipendium von Roche erhalten. C. Bokemeyer hat persönliche Honorare von Merck KGaA, Sanofi, Roche, BristolMyers Squibb, Servier/Pfizer, AstraZeneca, Bayer, Lilly/ ImClone, Merck Serono, Mundipharma, Bayer Schering Pharma, Hexal, Merck Sharp Dohme, GSO, AOK Gesundheitskasse und Pfizer sowie Zuwendungen von verschiedenen Unternehmen für klinische Studien und präklinische Untersuchungen unabhängig von der eingereichten Arbeit erhalten. P. Ivanyi hat persönliche Honorare von der Bayer Vital GmbH und Roche unabhängig von der eingereichten Arbeit erhalten. S. Loges hat Zuwendungen und persönliche Honorare von GenBio AS, persönliche Honorare von Boehringer Ingelheim, persönliche Honorare von AstraZeneca, persönliche Honorare von Chugai, persönliche Honorare von Novartis, persönliche Honorare von Abbvie, Zuwendungen und persönliche Honorare von BMS, persönliche Honorare von MSD, Zuwendungen und persönliche Honorare von Eli Lilly, Zuwendungen und persönliche Honorare von Roche Pharma, persönliche Honorare von Medac $\mathrm{GmbH}$, persönliche Honorare von Sanofi-Aventis unabhängig von der eingereichten Arbeit erhalten. P. Schirmacher hat Zuwendungen von Bayer im Rahmen der Studiendurchführung sowie Zuwendungen und persönliche Honorare von BMS, persönliche Honorare von MSD, Zuwendungen und persönliche Honorare von Roche, Zuwendungen und persönliche Honorare von AstraZeneca, persönliche Honorare von Incyte, persönliche Honorare von Ipsen, Zuwendungen von Falk, Zuwendungen von Chugai, Zuwendungen von Bayer und Zuwendungen von Novartis unabhängig von der eingereichten Arbeit erhalten. S. Bielack hat persönliche Honorare von Bayer Healthcare, Boehringer Ingelheim, Clinigen, Hoffmann-La Roche, Ipsen, Eli Lilly, Sensorion unabhängig von der eingereichten Arbeit erhalten. Er ist der Leiter der klinischen Prüfung in Deutschland für die SCOUTStudie (A Study to Test the Safety and Efficacy of the Drug Larotrectinib for the Treatment of Tumors With NTRK-fusion in Children, NCT02637687). T. T. W. Seufferlein hat persönliche Honorare von Bayer im Rahmen der Studiendurchführung sowie Zuwendungen und persönliche Honorare von Celgene, Zuwendungen und persönliche Honorare von Sanofi, Zuwendungen und persönliche Honorare von Amgen, Weiteres von Ipsen, persönliche Honorare von Pierre Fabre, persönliche Honorare von Servier, persönliche Honorare von Lilly, persönliche Honorare von Halozyme, persönliche Honorare und Weiteres von Merck unabhängig von der eingereichten Arbeit erhalten. N. Graf, L. C. Heukamp, M. Hummel, T. Klingebiel, S. Hettmer, C. Vokuhl und B. Wörmann geben an, dass kein Interessenkonflikt besteht.

Für diesen Beitrag wurden von den Autoren keine Studien an Menschen oder Tieren durchgeführt. Für die aufgeführten Studien gelten die jeweils dort angegebenen ethischen Richtlinien.

Open Access. Dieser Artikel wird unter der Creative Commons Namensnennung 4.0 International Lizenz veröffentlicht, welche die Nutzung, Vervielfältigung, Bearbeitung, Verbreitung und Wiedergabe in jeglichem Medium und Format erlaubt, sofern Sie den/die ursprünglichen Autor(en) und die Quelle ordnungsgemäß nennen, einen Link zur Creative Commons Lizenz beifügen und angeben, ob Änderungen vorgenommen wurden.
Die in diesem Artikel enthaltenen Bilder und sonstiges Drittmaterial unterliegen ebenfalls der genannten Creative Commons Lizenz, sofern sich aus der Abbildungslegende nichts anderes ergibt. Sofern das betreffende Material nicht unter der genannten Creative Commons Lizenz steht und die betreffende Handlung nicht nach gesetzlichen Vorschriften erlaubt ist, ist für die oben aufgeführten Weiterverwendungen des Materials die Einwilligung des jeweiligen Rechteinhabers einzuholen.

Weitere Details zur Lizenz entnehmen Sie bitte der Lizenzinformation auf http://creativecommons.org/ licenses/by/4.0/deed.de.

\section{Literatur}

1. Albert CM, Davis JL, Federman $\mathrm{N}$ et al (2019) TRK fusion cancers in children: a clinical review and recommendations for screening. J Clin Oncol 37:513-524

2. Amatu A, Sartore-Bianchi A, Siena S (2016) NTRK gene fusions as novel targets of cancer therapy across multiple tumour types. ESMO Open 1:e23

3. Ameline B, Saba KH, Kovac M et al (2020) NTRK fusions in osteosarcoma are rare and nonfunctional events. J Pathol Clin Res 6:107-112

4. Antonescu CR, Suurmeijer AJH, Zhang Let al (2015) Molecular characterization of inflammatory myofibroblastic tumors with frequent ALK and ROS1 gene fusions and rare novel RET rearrangement. Am J Surg Pathol 39:957-967

5. Bayer Vital Gmbh Fachinformation VITRAKVI ${ }^{\circledR}$.

6. Benayed R, Offin M, Mullaney K et al (2019) High yield of RNA sequencing for targetable kinase fusions in lung adenocarcinomas with no mitogenic driver alteration detected by DNA sequencing and low tumor mutation burden. Clin Cancer Res 25:4712-4722

7. Chou A, Fraser T, Ahadi M et al (2019) NTRK gene rearrangements are highly enriched in MLH1/PMS2 deficient, BRAF wild-type colorectal carcinomas-a study of 4569 cases. Mod Pathol 33:924-932

8. Christopoulos P, Endris V, BozorgmehrFetal (2018) EML4-ALK fusion variant V3 is a high-risk feature conferring accelerated metastatic spread, early treatment failure and worse overall survival in ALK(+) non-small cell lung cancer. Int J Cancer 142:2589-2598

9. clinicaltrials.gov. A study of Repotrectinib (TPX0005) in patients with advanced solid tumors harboring ALK, ROS1, or NTRK1-3 rearrangements (TRIDENT-1).Zugegriffen: 16. Nov. 2020

10. Cocco E, Scaltriti M, Drilon A (2018) NTRK fusionpositive cancers and TRK inhibitor therapy. Nat Rev Clin Oncol 15:731-747

11. CoccoE, Schram AM, KulickAetal (2019) Resistance to TRK inhibition mediated by convergent MAPK pathway activation. Nat Med 25:1422-1427

12. Demetri GD, Paz-Ares L, Farago AF et al (2018) Efficacy and safety of entrectinib in patients with NTRK fusion-positive (NTRK-fp) Tumors: pooled analysis of STARTRK-2, STARTRK-1 and ALKA-372001. Ann Oncol 29:LBA17

13. DGHO, DGP, GPOH, OeGHO, SGMO (2020) Positionspapier: NTRK-Inhibitoren als sog. tumoragnostische Arzneimittel. Empfehlungen zu Diagnostik und Therapie. https:// www.dgho.de/publikationen/stellungnahmen/ gute-aerztliche-praxis/ntrk-inhibitoren/tumoragnostische-arzneimittel-20200113.pdf. Zugegriffen: 16. Nov. 2020
14. Doebele RC, Drilon A, Paz-Ares L et al (2020) Entrectinib in patients with advanced or metastatic NTRK fusion-positive solid tumours: integrated analysis of three phase 1-2 trials. Lancet Oncol 21:271-282

15. Drilon A, Laetsch TW, Kummar Setal (2018) Efficacy of larotrectinib in TRK fusion-positive cancers in adults and children. NEngl J Med 378:731-739

16. Drilon A, Nagasubramanian R, Blake JF et al (2017) A next-generation TRK Kinase inhibitor overcomes acquired resistance to prior TRK Kinase inhibition in patients with TRK fusion-positive solid tumors. Cancer Discov 7:963-972

17. Drilon AE, Dubois SG, Farago AF et al (2019) Activity of larotrectinib in TRK fusion cancer patients with brain metastases or primary central nervous system tumors. JClin Oncol 37:2006

18. European Medicines Agency (2019) Committee for medicinal products for human use (CHMP). Assessment report VITRAKVI (Stand 25.07.2019, zuerst veröffentlicht 24.10.2019.)

19. Ferreri AJ, Govi S, Pileri SA et al (2012) Anaplastic large cell lymphoma, ALK-positive. Crit Rev Oncol Hematol 83:293-302

20. Gatalica Z, Xiu J, Swensen J et al (2019) Molecular characterization of cancers with NTRK gene fusions. Mod Pathol 32:147-153

21. Food and Drug Administration FDA approves entrectinib for NTRK solid tumors and ROS-1 NSCLC. https://www.fda.gov/drugs/ resources-information-approved-drugs/fdaapproves-entrectinib-ntrk-solid-tumors-andros-1-nsclc. Zugegriffen: 16. Nov. 2020

22. Gooskens SL, Houwing ME, Vujanic GM et al (2017) Congenital mesoblastic nephroma 50 years after its recognition: a narrative review. Pediatr Blood Cancer. https://doi.org/10.1002/pbc.26437

23. Halalsheh H, Mccarville MB, Neel M et al (2018) Dramatic bone remodeling following larotrectinib administration for bone metastasis in a patient with TRK fusion congenital mesoblastic nephroma. Pediatr Blood Cancer 65:e27271

24. Hechtman JF, Benayed R, Hyman DM et al (2017) Pan-Trk immunohistochemistry is an efficient and reliable screen for the detection of NTRK fusions. Am J Surg Pathol 41:1547-1551

25. Hong DS, BauerTM, Lee JJ et al (2019) Larotrectinib in adult patients with solid tumours: a multi-centre open-label, phase I dose-escalation study. Ann Oncol 30:325-331

26. Hong DS, Dubois SG, Kummar S et al (2020) Larotrectinib in patients with TRK fusion-positive solid tumours: a pooled analysis of three phase $1 / 2$ clinical trials. Lancet Oncol 21:531-540

27. Hsiao SJ, Zehir A, Sireci AN et al (2019) Detection of tumor NTRK gene fusions to identify patients who May benefit from tyrosine kinase (TRK) inhibitor therapy. J Mol Diagn 21:553-571

28. Hyman D, Kummar S, Farago A et al (2019) Abstract CT127: Phase I and expanded access experience of LOXO-195 (BAY2731954), a selective next-generation TRK inhibitor (TRKi). Cancer Res 79:CT127-CT127

29. Hyman DM, Van Tilburg CM, Albert CM et al (2019) Durability of response with larotrectinib in adult and pediatric patients with TRK fusion cancer. Ann Oncol 30:445PD

30. INFORM-Register. https://www.dkfz.de/de/ inform/inform-register.html. Zugegriffen: 16 . Nov 2020

31. Kirchner M, Glade J, Lehmann U et al (2020) NTRK testing: first results of the QuiP-EQA scheme and a comprehensive map of NTRK fusion variants and their diagnostic coverage by targeted RNA- 
based NGS assays. Genes Chromosomes Cancer 59:445-453

32. Kummar S, Lassen UN (2018) TRKinhibition: a new tumor-agnostic treatment strategy. Target Oncol 13:545-556

33. Laetsch TW, Dubois SG, Mascarenhas L et al (2018) Larotrectinib for paediatric solid tumours harbouring NTRK gene fusions: phase 1 results from a multicentre, open-label, phase $1 / 2$ study. Lancet Oncol 19:705-714

34. Laetsch TW, Nagasubramanian R, Casanova M (2018) Targeting NTRK fusions for the treatment of congenital mesoblastic nephroma. Pediatr Blood Cancer. https://doi.org/10.1002/pbc.26593

35. Lassen UN, Albert CM, Kummar S et al (2018) Larotrectinib efficacy and safety in TRK fusion cancer: an expanded clinical dataset showing consistency in an age and tumor agnostic approach. Ann Oncol 29:4090

36. Lee SJ, Kim NKD, Lee S-H et al (2017) NTRK gene amplification in patients withmetastatic cancer. Precis Future Med 1:129-137

37. Lin JJ, Zhu VW, Yoda S et al (2018) Impact of EML4ALK variant on resistance mechanisms and clinical outcomes in ALK-positive lung cancer. J Clin Oncol 36:1199-1206

38. Lindeman NI, Cagle PT, Aisner DL et al (2018) Updated molecular testing guideline for the selection of lung cancer patients for treatment with targeted tyrosine kinase inhibitors: guideline from the College of American Pathologists, the International Association for the Study of Lung Cancer, and the Association for Molecular Pathology. J Mol Diagn 20:129-159

39. Liu D, Offin M, Harnicar S et al (2018) Entrectinib: an orally available, selective tyrosine kinase inhibitor for the treatment of NTRK, ROS1, and ALK fusion-positive solid tumors. Ther Clin Risk Manag 14:1247-1252

40. LOGGIC Core-Plattform. https://cccc.charite. de/fileadmin/user_upload/microsites/m cc10/ CCCC/3_Forschung/Klinische_Studien/HITLOGGIC 622073.pdf.Zugegriffen:16. Nov. 2020

41. LOGGIC Core-Plattform. https://www.kitzheidelberg.de/fuer-aerzte/klinische-studien/ kitz-clinical-trial-unit/translational-trial-group/. Zugegriffen: 16. Nov. 2020

42. Marchio C, Scaltriti M, Ladanyi Met al (2019) ESMO recommendations on the standard methods to detect NTRK fusions in daily practice and clinical research. Ann Oncol 30:1417-1427

43. Naito Y, Mishima S, Akagi K et al (2020) Japan society of clinical oncology/Japanese society of medical oncology-led clinical recommendations on the diagnosis and use of tropomyosin receptor kinase inhibitors in adult and pediatric patients with neurotrophic receptor tyrosine kinase fusionpositive advanced solid tumors, cooperated by the Japanese society of pediatric hematology/ oncology. Int J Clin Oncol 25:403-417

44. Okamura R, Boichard A, Kato S et al (2018) Analysis of NTRK alterations in pan-cancer adult and pediatric malignancies: implications for NTRKtargeted therapeutics. JCO Precis Oncol. https:// doi.org/10.1200/PO.18.00183

45. Orbach D, Rey A, Cecchetto G et al (2010) Infantile fibrosarcoma: management based on the European experience. J Clin Oncol 28:318-323

46. Penault-Llorca F, Rudzinski ER, Sepulveda AR (2019) Testing algorithm for identification of patients with TRK fusion cancer. J Clin Pathol 72:460-467

47. Pfarr N, Kirchner M, Lehmann U et al (2020) Testing NTRK testing: Wet-lab and in silico comparison of RNA-based targeted sequencing assays. Genes Chromosomes Cancer 59:178-188

48. Pietrantonio F, Di Nicolantonio F, Schrock AB et al (2017) ALK, ROS1, and NTRK rearrangements in metastatic colorectal cancer. J Natl Cancer Inst. https://doi.org/10.1093/jnci/djx089

49. Robinson GW, Gajjar AJ, Gauvain KM et al (2019) Phase $1 / 1 \mathrm{~B}$ trial to assess the activity of entrectinib in children and adolescents with recurrent or refractory solid tumors including central nervous system (CNS) tumors. J Clin Oncol 37:10009

50. Rolfo C, Dziadziuszko R, Doebele RC et al (2019) Updated efficacy and safety of entrectinib in patients with NTRK fusion-positive tumors: Integrated analysis of STARTRK-2, STARTRK-1 and ALKA-372-001. Ann Oncol 30:476P

51. Rosen EY, Goldman DA, Hechtman JF et al (2019) TRK fusions are enriched in cancers with uncommon histologies and the absence of canonical driver mutations. Clin Cancer Res 26:1624-1632

52. Rosenbaum JN, Bloom R, Forys JT et al (2018) Genomic heterogeneity of ALK fusion breakpoints in non-small-cell lung cancer. Mod Pathol 31:791-808

53. Schram AM, Chang MT, Jonsson P et al (2017) Fusions in solid tumours: diagnostic strategies, targeted therapy, and acquired resistance. Nat Rev Clin Oncol 14:735-748

54. Scott LJ (2019) Larotrectinib: first global approval. Drugs 79:201-206

55. Siena S, Doebele RC, Shaw AT et al (2019) Efficacy of entrectinib in patients (pts) with solid tumors and central nervous system (CNS) metastases: Integrated analysis from three clinical trials. J Clin Oncol 37:3017

56. Solomon JP, Hechtman JF (2019) Detection of NTRK fusions: merits and limitations of current diagnostic platforms. Cancer Res 79:3163-3168

57. Solomon JP, Linkov I, Rosado A et al (2020) NTRK fusion detection across multiple assays and 33,997 cases: diagnostic implications and pitfalls. Mod Pathol 33:38-46

58. Studienportal Pädiatrische Onkologie Und Hämatologie. https://www.kinderkrebsinfo.de/e1676/ e9032/index_ger.html?preview=preview. Zugegriffen: 16 . Nov. 2020

59. Tan F, Thiele CJ, Li Z (2014) Neurotrophin signaling in cancer. In: Kostrzewa RM (Hrsg) Handbook of Neurotoxicity. Springer, New York, NY, S 1825-1847

60. Taylor J, Pavlick D, Yoshimi A et al (2018) Oncogenic TRK fusions are amenable to inhibition in hematologic malignancies. J Clin Invest 128:3819-3825

61. Vaishnavi A, Le AT, Doebele RC (2015) TRKing down an old oncogene in a new era of targeted therapy. Cancer Discov 5:25-34

62. Van Tilburg CM, Dubois SG, Albert CM et al (2019) Larotrectinib efficacy and safety in pediatric TRK fusion cancer patients. JClin Oncol 37:10010

63. Van Tilburg CM, Pfaff E, Pajtler KW et al (2020) The pediatric precision oncology study INFORM: clinical outcome and benefit for molecular subgroups.J Clin Oncol 38:LBA10503

64. Vokuhl C, Nourkami-Tutdibi N, Furtwangler R et al (2018) ETV6-NTRK3 in congenital mesoblastic nephroma: a report of the SIOP/GPOH nephroblas toma study. Pediatr Blood Cancer. https://doi.org/ 10.1002/pbc.26925

65. Volckmar AL, Leichsenring J, Kirchner Met al (2019) Combined targeted DNA and RNA sequencing of advanced NSCLC in routine molecular diagnostics: Analysis of the first 3,000 Heidelberg cases. Int J Cancer 145:649-661
66. Wiesner T, He J, Yelensky R et al (2014) Kinase fusions are frequent in Spitz tumours and spitzoid melanomas. Nat Commun 5:3116

67. Wong D, Yip S, Sorensen PH (2019) Methods for identifying patients with tropomyosin receptor Kinase (TRK) fusion cancer. Pathol Oncol Res 26:1385-1399

68. Woo CG, Seo S, Kim SW et al (2017) Differential protein stability and clinical responses of EML4 ALK fusion variants to various ALK inhibitors in advanced ALK-rearranged non-small cell lung cancer. Ann Oncol 28:791-797

69. Wu G, Diaz AK, Paugh BS et al (2014) The genomic landscape of diffuse intrinsic pontine glioma and pediatric non-brainstem high-grade glioma. Nat Genet 46:444-450

70. Xia H, Xue X, Ding Het al (2020) Evidence of NTRK1 fusion as resistance mechanism to EGFR TKI in EGFR+ NSCLC: results from a large-scale survey of NTRK1 fusions in Chinese patients with lung cancer. Clin Lung Cancer 21:247-254

71. Yanai I, Derti A, Delisi C (2001) Genes linked by fusion events are generally of the same functional category: a systematic analysis of 30 microbial genomes. Proc Natl Acad SciU SA 98:7940-7945

72. Zehir A, Benayed R, Shah RH et al (2017) Mu landscape of metastatic cancer revealed from prospective clinical sequencing of 10,000 patients NatMed 23:703-713 